\title{
Time use and happiness: Evidence across three decades
}

\author{
Jeehoon Han $^{*} \&$ Caspar Kaiser ${ }^{* *}$
}

This version: October 2021

\begin{abstract}
We use diary data from representative samples of Americans to examine historical trends in happiness at both the individual activity-level and aggregate-level. At the activity-level, domestic work and social care produce more happiness today compared to 1985. Watching TV produces less happiness than it used to. At the aggregate level, we combine information on happiness and time allocation to construct a measure of 'time-weighted happiness'. Over the last 35 years, women's time-weighted happiness has improved significantly relative to men's. This observation is in stark contrast to previous work which showed a decline in women's relative wellbeing. To explain this, we compare the determinants of life satisfaction a more global measure on which most previous work is built - with our measure of time-weighted happiness. Time-weighted happiness and life satisfaction turn out to only be weakly correlated. Moreover, although we obtain strong associations of income and employment status with life satisfaction, no such associations can be observed for time-weighted happiness. Thus, the determinants and historical patterns of momentary happiness and more global measures fail to coincide. This highlights the importance of distinguishing and striking a balance between these wellbeing measures when analysing and designing policy.
\end{abstract}

Keywords: time use; happiness; life satisfaction; subjective wellbeing; gender gap

\footnotetext{
${ }^{*}$ School of Economics, Zhejiang University. jeehoonhan3@gmail.com ${ }^{* *}$ Wellbeing Research Centre \& Institute for New Economic Thinking, University of Oxford. caspar.kaiser@hmc.ox.ac.uk. We thank Jan-Emmanuel De Neve, Carol Graham, Daniel Hamermesh, Mark Fabian, Lucia Macchia, Joel McGuire, Alberto Prati, Wei Qian, and Julia Schmidtke, as well as seminar participants at Zhejiang University, the Chinese Economists Society 2021 conference, and the ISOQOL 2021 annual conference for their helpful comments. We also thank Jonathan Gershuny for providing the 1985 US and 1986 UK time use data.
} 


\section{Introduction}

How we spend our time determines our wellbeing. Historical trends in wellbeing may thus either be driven by changes in the activities we spend our time on, or by changes in how valuable we find individual activities. Several previous works documented trends in time allocation over time and across countries (Juster and Stafford, 1991; Robinson and Godbey, 1999; Aguiar and Hurst, 2007; Ramey, 2007; GimenezNadal and Sevilla, 2012; Sevilla et al., 2012; Pepin et al., 2018) and a number of studies quantified the value of non-market time using market wages (Bryant and Zick, 1985; Bonke 1992; Jenkins and O'Leary, 1996; Frazis and Stewart, 2011; Han et al., 2020).

We take a more direct approach and capture the value of people's time by using survey data on self-reported happiness. Specifically, we combine the underused 1985 American's Use of Time Project (AUTP) and the wellbeing module of the 2010, 2012, and 2013 American Time Use Surveys (ATUS). In both surveys, individuals rate the level of enjoyment or happiness of the activities they engaged in on the preceding day. Data obtained via this so-called "day reconstruction method" has been shown to closely approximate realtime data based on experience sampling (Kahneman et al., 2004).

With this data, we show how the enjoyability of different activities has changed over time and analyse gendered trends in average happiness since 1985 . We thus make three contributions.

First, we quantify changes in affective experience over the last three decades. Unlike previous studies that examined correlations between happiness and activities (Robinson and Godbey, 1999; Gershuny, 2011; Zuzanek and Zuzanek, 2015; Gershuny and Sullivan, 2019), we estimate the relationship between happiness and activities using an individual fixed effects model that accounts for potential confounding factors which may affect both the choice of activity and the reported level of happiness. We find significant improvements in the enjoyability of domestic work, shopping, and social care. In contrast, watching TV produces less happiness today than it used to do. Strikingly, levels and changes in time-allocation are largely uncorrelated with happiness levels during these activities.

Second, we document historical trends in time-weighted happiness. For each year, we measure average happiness by combining information on individuals' time allocation across activities with fixed effectsadjusted estimates of activity-level happiness. We thereby complement previous studies that relied on more standard measures of wellbeing (Blanchflower and Oswald, 2004a; Stevenson and Wolfers, 2009). In contrast to these studies, we find robust evidence that men's time-weighted happiness has declined relative to women's happiness over the last 35 years. This relative decline is largely driven by unfavourable shifts in time allocation, rather than a decrease in the enjoyability of individual activities.

Third, we analyse how time-weighted happiness differs from life satisfaction. In doing so, we seek to explain the conflict between our results and those from previous works. It turns out that most of the variation in life satisfaction across individuals does not reflect differences in time-weighted happiness. Moreover, several individual characteristics that are positively correlated with life satisfaction have no or a negative association with time-weighted happiness. For example, we find no associations of income and employment status with time-weighted happiness. This again contrasts with previous works that used more global measures of wellbeing (Layard et al., 2008; Kahneman et al., 2010; Jebb et al., 2018). Our results therefore suggest that global measures of happiness and life satisfaction, which are the dominant data sources in work on wellbeing, provide an incomplete, and possibly misleading, picture of wellbeing.

\section{Empirical Approach}

\subsection{Data}

Our analyses primarily rely on the 1985 "Americans' Use of Time Project" (AUTP) and the 2010, 2012, and 2013 "American Time Use Surveys" (ATUS). The 1985 AUTP data was collected via mail-back throughout the year and is representative of private households in the US. Respondents rate the level of 
enjoyment for all activities they engaged during a day. Ratings are recorded on a scale from 0 (dislike a great deal) to 10 (enjoy a great deal). The ATUS sample was collected using telephone interviews and is representative of individuals aged 15+ in private households in the US. In years 2010, 2012, and 2013, the ATUS asked respondents to report their happiness during three randomly chosen episodes. Ratings are recorded on a scale of 0 (not at all) to 6 (very). When analysing trends in time allocation, we additionally use the 1994-1995 "National Time-Diary Study" and the 2003-2019 ATUS. We obtain all these datasets from the IPUMS database (Fisher et al., 2018; Hofferth et al., 2020). ${ }^{1}$ The surveys also collected sociodemographic characteristics, including age, sex, education, employment status, and income. Appendix Table 1 provides descriptive statistics on each of these variables.

In supplemental analyses, we replicate our results with data from the UK. There, we use the UK 1986 "Unilever Market Research Survey" and the 2014-15 waves "UK Time-Use Survey" (UKTUS), which collected time-use diaries along with happiness measures that are comparable to those from the US. We additionally use the 2000 wave of the UKTUS when examining trends in time-weighted happiness in the UK.

Fewer activity categories are available in our 1985 AUTP data than in the 2010-2013 ATUS data. To make activity codes comparable, we first convert activity codes into 92 activity codes defined by the American Heritage Time Use Study, which are designed to be harmonized across years (Fischer et al., 2018). To make the analysis tractable, we further classify the 92 activity codes into 13 broad activity categories where each category consists of similar activities: market work (including work-related activities), domestic work, shopping, travel (excluding work-related travel), eating, out-of-home leisure, watching TV, in-home leisure (excluding watching TV), social care (child/elderly care), education, religious/civic activities, personal care, and sleeping. Appendix Table 2 reports a full list of activities within each of the 13 categories.

Our sample excludes individuals aged below 18. Moreover, we exclude individuals that have missing values on age, sex, and marital status, or individuals with low-quality diaries, (i.e. reporting less than 5 different episodes, or failing to report on eating and sleeping, or $3+$ missing hours). These restrictions drop about $6 \%$ of the sample.

\subsection{Accounting for Demographic Changes and for Changes in Question Format}

The 1985 AUTP provides survey weights to match the sample with Census data for the percentage of men and women who work full time. Similarly, the ATUS survey weights adjust the sample to match Census estimates for age, gender, education, ethnicity, and household composition. These weights also adjust the sample to represent each day of the week equally.

To study historical trends in happiness that are not driven by changes in the demographic composition of the population, we reweight the ATUS so that the demographic composition matches those observed in the 1985 AUTP. Specifically, we first divide the 1985 AUTP sample into 32 cells defined by four demographic variables: age (18-29, 30-39, 40-49, 50+), education (H.S. degree or less, some college or above), gender, and marital status (single, married). We then use the share in each of the 32 cells as our fixed demographic weights. ${ }^{2}$

The 1985 AUTP and the 2010-2013 ATUS data use different response scales. In 1985 a 0-10 scale was used, while in 2010-2013 a 0-6 scale was used. To construct a measure that is consistent over time, we convert the original scores into a common 3-point scale with a distribution that remains stable between 1985 and 2010-2013 (see Appendix Figure 1). Specifically, scores 0 to 2 from the 11-point 1985 survey are converted to a 0 , scores of 3-8 are converted to a 1, and scores 9-10 are converted to a 2 . For the 2010-2013

\footnotetext{
${ }^{1}$ Because the IPUMS version does not contain enjoyment information, we incorporate that information from the original 1985 data.

${ }^{2}$ However, using survey weights, instead of using fixed demographic weights, does not alter our qualitative conclusions (Appendix Figure 16).
} 
data, we convert the original scores of 0-1 into a 0 , scores of 2-5 are converted to a 1, and scores of 6 are converted to a 2. Collapsing the 1985 and the 2010-2013 data in this manner entails the assumption that, although question wordings (enjoyment vs. happiness) and survey methods (mail-back vs. phone) are different across the two surveys, each of the collapsed categories refer to a similar quality of affective experience across the surveys. ${ }^{3}$

It is thus crucial to test the sensitivity of our results against these assumptions. We run three tests. First, we estimate ordered probit regressions in which we only assume that the location of a single threshold is the same across surveys. Second, we estimate sets of OLS regressions based on all possible dichotomizations of our happiness measures. Third, we evaluate the robustness of results to using a 4-point common happiness measure, instead of a 3-point happiness measure. These tests show that, although estimates of absolute trends in happiness are affected by the way in which the data is harmonized, estimates of gender differences in trends are highly robust across specifications and estimation procedures.

\subsection{Accounting for Individual Fixed Effects}

Individual characteristics like health or personality traits may affect both underlying happiness levels and the choice of activity (Hurst, 2009). For example, extroverts may generally report a higher level of happiness than introverts regardless of the current activity. Also, extroverts may be more likely to engage in out-of-home leisure activities than introverts. In this case, the positive association between out-of-home leisure and happiness would be confounded by personality traits. Previous work on time-use and happiness may have suffered from such confounding.

To address this bias, we exploit the fact that happiness is reported for multiple episodes for the same individual, and estimate the following individual fixed effect (FE) model:

$$
h_{i j}=\theta_{i}+\sum_{j}^{J_{i}} \beta_{j t}^{(g)} \mathbb{1}\{\text { Activity }=j\}_{i}+\epsilon_{i j}
$$

where $h_{i j}$ is the individual $i$ 's reported happiness score for activity $j$ among a set $J_{i}$ reported activities. $\theta_{i}$ is an individual fixed effect (FE) which absorbs any variation in happiness due to characteristics that are invariant within an individual and across the diary day. $\mathbb{1}\{\text { Activity }=j\}_{i}$ is an indicator variable for activity $j$, and $\varepsilon_{i j}$ is an unobserved error. $\beta_{j t}^{(g)}$ captures average FE-adjusted happiness for activity $j$ in year $t$ for group $g$. In our main analyses, $g$ indexes over gender. Years $t$ range over 1985, 2010, 2012, and 2013. In Appendix Figure 2, we show that for both men and women, FE-adjusted happiness during shopping and education is greater than mean unadjusted happiness. Contrariwise, FE-adjusted happiness during civic/religious activities is smaller than without fixed effects. Thus, individuals who are more likely to report having been shopping (attending civic/religious events) tend to have a low (high) underlying happiness level regardless of activities. Hence, the correlation between activities and reported happiness is confounded by unobserved individual characteristics.

\section{Main Results}

\subsection{Changes in Activity-Level Happiness and Time-Use}

Using the FE-adjusted happiness estimates described above, we first examine levels and historical changes in happiness during different activities.

\footnotetext{
${ }^{3}$ Since respondents are not asked about a global concept of "happiness" - as is asked in standard surveys like the General Social Survey -, but instead about happiness during a particular activity, we think that this assumption is reasonable.
} 
Figure 1. FE-adjusted happiness and time-use, 1985 and 2013.
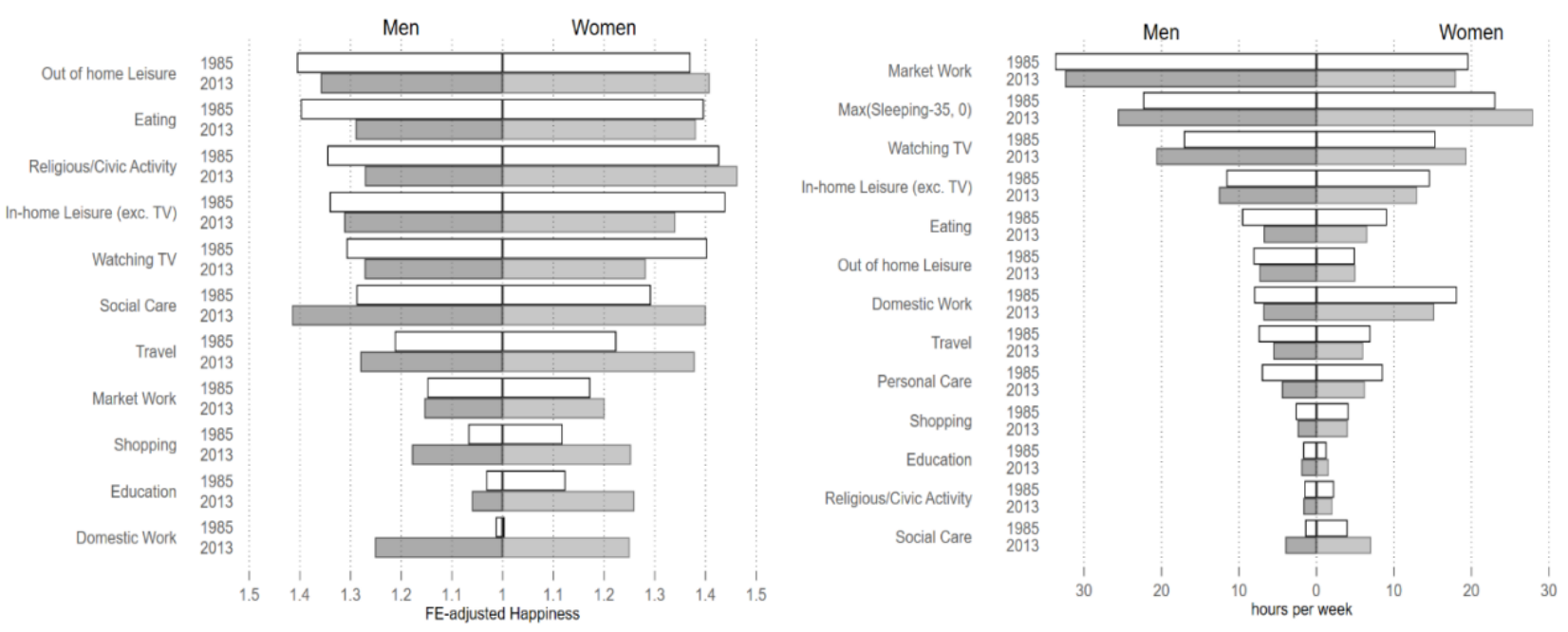

Note: The left panel shows mean FE-adjusted levels of happiness across activities for men and women (estimated using equation (1)). The right panel shows average weekly time-use on each activity.

The left panel in Figure 1 shows average activity-level happiness in 1985 and $2013 .{ }^{4}$ For both genders, leisure results in much greater happiness than market and non-market work, consistent with earlier studies (Robinson and Godbey, 1999; Krueger et al., 2009). Eating, social care, civic/religious activities also rank high in happiness, while educational activities rank very low in happiness for both men and women in both 1985 and 2013. Compared to 1985, several activities produce more happiness in 2013. Those include shopping, education, market work, and travel. Particularly pronounced are increases associated with social care and domestic work. These improvements may reflect advances in household technologies (e.g., the quality of washing and drying machines) and improvements in housing conditions over time, which together may have made domestic work and social care easier and more pleasant.

Men's and women's happiness during out-of-home leisure and civic/religious activities moved in opposing directions. Compared to 1985, women are happier during out-of-home leisure and religious/civic activities. In contrast, men find less joy in these activities in 2013 than in 1985.

In-home leisure, eating, and watching TV have become less enjoyable for both genders. Given that the nature of these activities has changed little over time, a decline in the extent to which they produce happiness may reflect changes in opportunities for other leisure activities. For example, we find that the decline in the enjoyability of in-home leisure and watching TV is more salient for women, who also experienced an increase in happiness for out-of-home leisure and civic/religious activities.

The right panel in Figure 1 reports average weekly hours spent on each activity in 1985 and 2013. In 1985 men spent significantly more time doing market work (34 hours) than women (20 hours). However, women spent more time doing domestic work (18 hours) than men ( 8 hours). Watching TV and other in-home leisure activities jointly took up about 30 hours per week in 1985 for both genders. Among other activities, women spent more time on social care, on shopping, and on civic/religious activities. Men spent more time on eating, out-of-home leisure, travel, and education than women in 1985.

Since then, the allocation of time across activities has shifted substantially. Time spent sleeping and watching TV increased by more than 3 hours per week, and time spent on social care increased by more

\footnotetext{
${ }^{4}$ Appendix Figures 3 and 10 respectively replicate Figure 1 using a more detailed set of 46 activity categories, and using an ordered probit regression.
} 
than 2 hours. Although these trends are observed across genders, they are more pronounced among women. We also observe a decline in time-spent on domestic work, which again is more pronounced among women ( 3 hours). This change may have been driven by shifts in gender roles and/or improvements in domestic technology. Time spent on in-home leisure changed in opposite directions across genders: Men's time allocation increased by one hour, whereas women spend 1.6 hours less.

Given these changes in the enjoyability of individual activities and the time Americans spend on them, we may wonder whether time-allocation and enjoyability are correlated. If individuals choose activities to maximize happiness subject to monetary constraints, we should expect that the economic growth of the last three decades enabled individuals to spend more time on activities that generate greater happiness.

Thus, in Figure 2, we examine the relationship between time-use and FE-adjusted happiness.

Figure 2. Relationship between FE-adjusted happiness and time-use, 1985 and 2013.
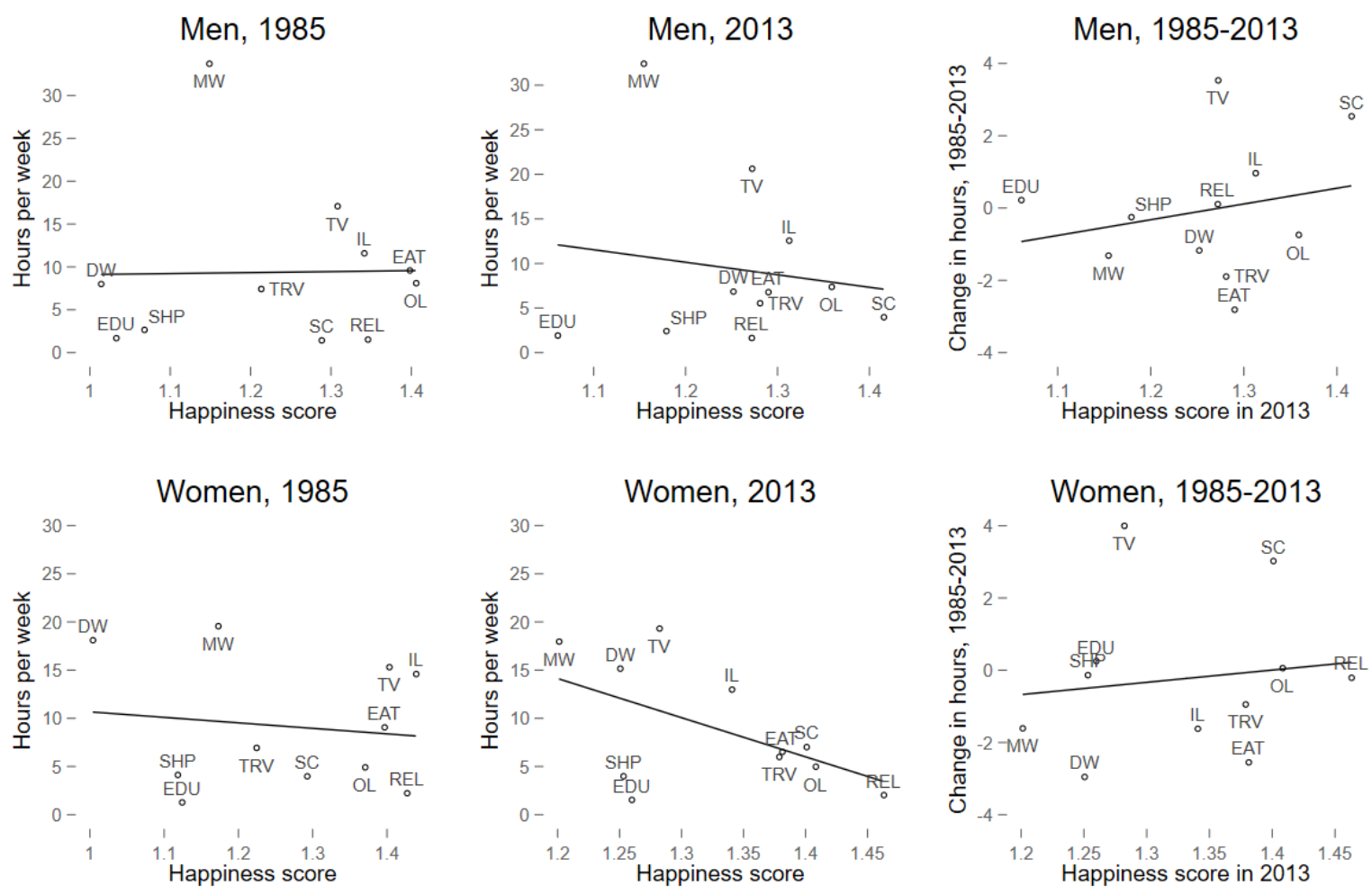

Note: The left-most panels show the relationship between time-use and FE-adjusted happiness in 1985 for men (top) and women (bottom). The middle panels show the same relationship for 2013. The right-most panels show the association between the change in time allocation and FE-adjusted happiness levels in 2013. The solid lines are regression lines of the number of hours per week on the estimated FE-adjusted happiness levels. MW: market work, DM: domestic work, SHP: shopping, TRV: travel excluding work related travel, EAT: eating, OL: out of home leisure, TV: watching TV, IL: in home leisure excluding watching TV, SC: social care, EDU: education, REL: civic/religious activities. 
Surprisingly, for 1985, we find no significant association between happiness and time allocation across activities (men: $\beta=1.13 ; p=0.96$; women: $\beta=-5.70 ; p=0.71$ ). ${ }^{5}$ In 2013 , this association even turned negative for both men $(\beta=-14.03 ; p=0.67)$ and women $(\beta=-40.63 ; p=0.09)$. We find no significant associations when regressing the change in time-allocation on levels of happiness in 2013 (men: $\beta=4.36$; $p=0.50$; women: $\beta=3.40 ; p=0.70$ ).

One possible explanation for the surprisingly weak relationship between time-use and happiness is that when choosing activities, people give greater priority to other factors, including family wellbeing, financial security, or health (Benjamin et al., 2014). However, the relationship between happiness and time-use is not even positive when comparing watching TV and in-home leisure. These two activities are likely to be close substitutes and are similar in their price. Nevertheless, people spend more time on watching TV than on in-home leisure, despite watching TV resulting in less happiness. Therefore, a more fitting explanation may be that, in addition to monetary constraints, people also face social and psychological limitations (e.g., cognitive effort) when choosing happiness-inducing activities (Crawford and Godbey, 1987).

One potential concern with these estimates is that they are based on 13 broad activity categories within which happiness trends may differ across individual activities. In Appendix Figure 4, we therefore replicate Figure 2, using detailed 46 activity categories. When performing this more disaggregated analysis, we again find weak relationship between happiness and time allocation.

Finally, although our FE-adjusted happiness estimates are preferable from the perspective of accounting for person-invariant characteristics, we may worry that since the estimates of Figure 2 associate averages in time allocation and happiness, they do not directly model individuals' choices. Appendix Figure 5 addresses this worry and shows the results of a set of local polynomial regressions of time allocation on reported happiness by year and gender. There, we again find that the time allocated to a given activity and the enjoyability of that activity are largely unrelated.

\subsection{Historical Trends in Time-Weighted Happiness Across Men and Women}

We now ask whether there are differential historical trends in time-weighted happiness across men and women. Time-weighted happiness (TWH) is operationalised as the FE-adjusted activity-level happiness estimates from equation (1), weighted by the average time spent in each activity:

$$
T W H_{t}^{(g)}=\sum_{j} \hat{\beta}_{j t}^{(g)} \frac{\text { time }_{j t}^{(g)}}{\text { total time }_{t}^{(g)}}
$$

Here, $\hat{\beta}_{j t}^{(g)}$ is the FE-adjusted happiness, estimated from equation (1), time $e_{j t}^{(g)}$ is the average time spent on activity $j$ in year $t$ and group $g$. Average total time reported in year $t$ is given by total time $e_{t}^{(g)}$. Initially, $g$ indexes over gender. Additional subgroups are considered in the next section. For years $t$ between 1995 and 2009 we interpolate activity-level happiness using the happiness estimates of 1985, 2010, 2012, and 2013, and weighting each of these estimates by their inverse distance to year $t$ (Cox, 2016). We assign to year 2011 the average of activity happiness estimates in 2010 and 2012. All years after 2013 are assigned the happiness estimates of 2013.

Our definition of time-weighted happiness approximates the concept of "objective happiness" proposed by Kahneman et al (1997) and is closest to a Benthamite conception of wellbeing. In contrast, previous studies that examine trends in subjective wellbeing in the U.S. primarily relied on the General Social Survey (GSS) or Gallup Surveys, which ask a single global question on happiness or life satisfaction. For instance, the GSS asks the following question: "Generally speaking, how happy would you say you are - very happy,

${ }^{5}$ The $\beta$ coefficients indicate the expected change in time-use (in minutes) for a one-point change on our three-point happiness scale. 
Figure 3. Time-weighted happiness by gender, 1985-2019.

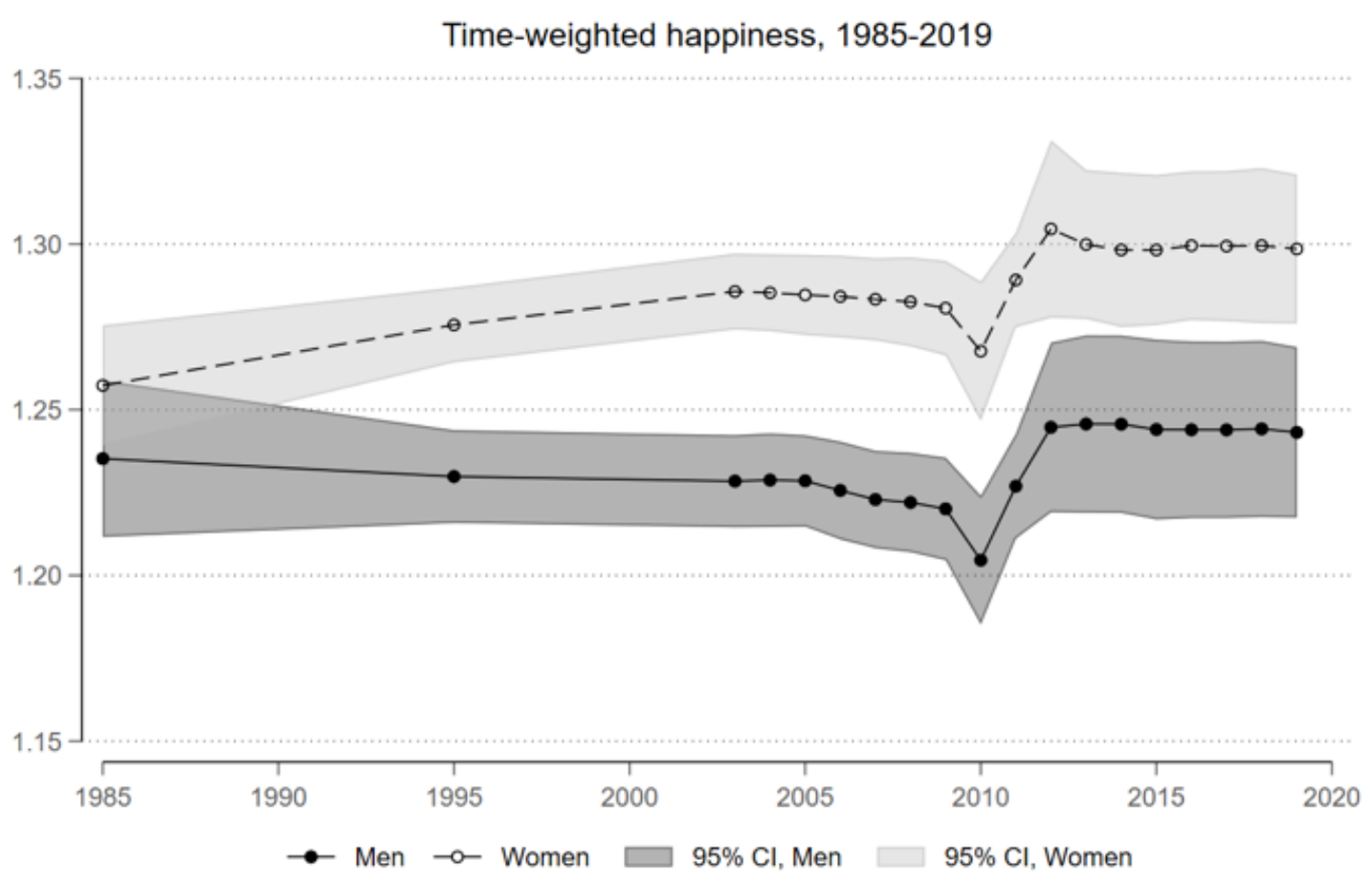

Note: This figure plots trends in time-weighted happiness between 1985 and 2019. Shaded regions are 95\% confidence intervals. Time-weighted happiness is defined as the weighted average of the activity-level FE-adjusted happiness, with weights being the fraction of total time spent on activities. FE-adjusted happiness estimates are based on data from 1985, 2010, 2012, and 2013. We interpolate the activity level happiness for years 1995-2009, and 2011 using the weighted average of happiness estimates from years 1985, 2010, 2012, and 2013, with weights being the inverse of the distance between values. For years after 2013, we assign the happiness estimates in 2013. Estimates are additionally weighted using fixed demographic weights.

fairly happy, not too happy?". Answering this question is likely to involve significant cognitive effort and abstract thought. Respondents may therefore resort to simplifying heuristics when answering such questions, yielding potentially biased responses (Schwarz \& Strack, 1999). Such measures may therefore fail to reflect the level of happiness that one actually experienced (Kahneman, 1999).

We are aware of one study that examined historical trends in time-weighted happiness. Krueger (2007) combined affective experiences across activities with historical time-use data and found that between 1985 and 2005 there were shifts in time allocation from unpleasant activities for men but not for women. However, the analysis of Krueger (2007) assumes that the levels of affect across activities did not change over time. Instead, his analysis assigns activity-level affect in 2006 to all earlier years.

Figure 3 reports changes in time-weighted happiness in the U.S. over the past 35 years. Earlier work found a decline in women's happiness relative to men over time (Blanchflower and Oswald, 2004a; Stevenson and Wolfers, 2009), or little change in the gender gap (Krueger, 2007). In contrast, we find that women have experienced a clear increase in happiness relative to men over the last 35 years. While there was no 
Figure 4. Time-weighted happiness when constraining activity-level happiness (left panel) or time-use (right panel) to be equal across genders.
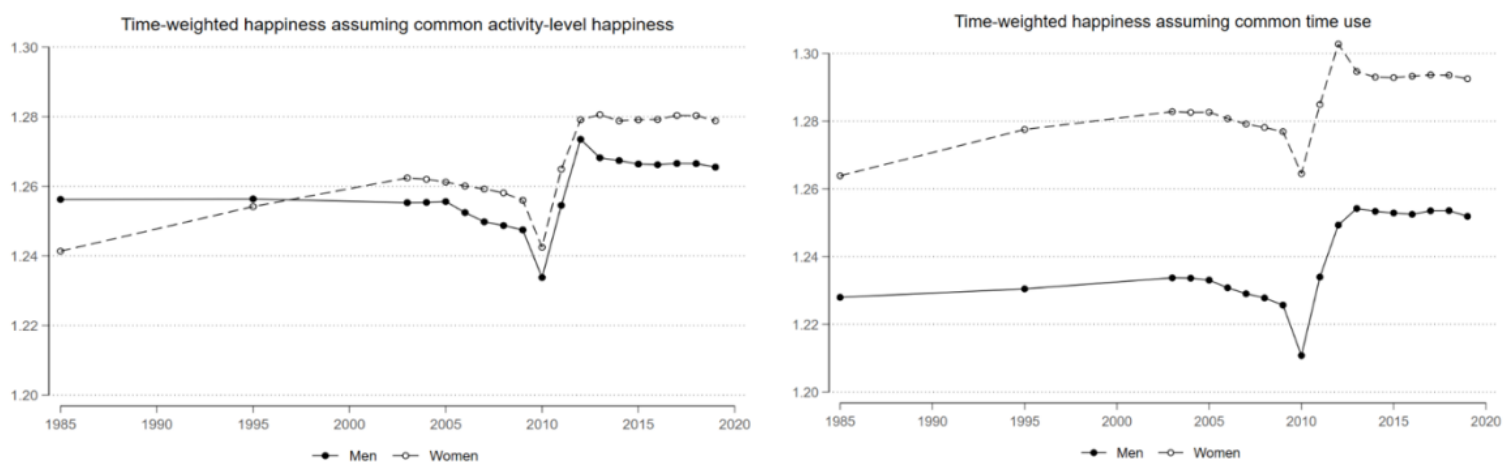

Note: This figure plots changes in the aggregate happiness by gender when constraining activity-level happiness (right panel) or time-use (left panel) to be equal across genders. FE-adjusted happiness estimates are based on data from 1985, 2010, 2012, and 2013. Happiness estimates in all other years are inter- or extrapolated as described in the note to Figure 3. Estimates are weighted using fixed demographic weights.

significant gender gap in $1985\left(T W H_{1985}^{(w)}-T W H_{1985}^{(m)}=0.022 ; p=0.140\right)$, the gap more than doubled and became significant at the $1 \%$ level by $2019\left(T W H_{2019}^{(w)}-T W H_{2019}^{(m)}=0.055 ; p=0.007\right){ }^{6}$

There are two channels through which women may have made gains in time-weighted happiness relative to men. First, women, relative to men, may increasingly spend more time on enjoyable activities (differential trends in time-use). Second, women, relative to men, may enjoy activities more today than they used to do in 1985 (differential trends in activity-level happiness). To evaluate the relative importance of these channels we decompose the gender gap into these two components. Appendix A provides a proof of this decomposition.

The left panel of Figure 4 shows trends in time-weighted happiness when constraining the coefficients from equation (1) to be equal across genders in a given year. In other words, we impose $\beta_{j t}^{(w)}=\beta_{j t}^{(m)}$ in equation (1) for all $j, t$, to compute a new constrained measure of time-weighted happiness $\left(\overline{T W H}_{t}^{(g)}\right)$. The figure thereby shows the contribution of gendered trends in time-use to the overall time-weighted happiness trend shown in Figure 3. Figure 4 makes evident that if both genders had always derived equal happiness from individual activities, women's time-weighted happiness in 1985 would have been lower than men's $\left(\overline{T W H}_{1985}^{(w)}-\overline{T W H}_{1985}^{(M)}=-0.015\right)$. However, by 2019 , this pattern would have reversed, with women showing more time-weighted happiness $\left(\overline{T W H}_{2019}^{(w)}-\overline{T W H}_{2019}^{(M)}=0.013\right)$. Thus, relative to men, the amount of time women spent on enjoyable activities has increased over the last 35 years.

The right panel of Figure 4 shows trends in time-weighted happiness when constraining time-use to be equal across genders in a given year, ${ }^{7}$ yielding another constrained measure of time-weighted happiness $\left(\widetilde{T W H}_{t}^{(g)}\right)$. This figure shows the contribution of gendered trends in the enjoyability of individual activities to the overall happiness trend. We find that if men and women had always spent their time equally, then women would have experienced much higher levels of time-weighted happiness in 1985 already. This gap

\footnotetext{
${ }^{6}$ Appendix Figure 6 shows that the increasing gender gap in time-weighted happiness is even more apparent when using a more disaggregated set of 46 activity categories.

${ }^{7}$ I.e., we assign the average time allocation of men and women to both genders.
} 
marginally increased between 1985 and $2019\left(\widetilde{T W H}_{1985}^{(w)}-\widetilde{T W H}_{1985}^{(m)}=0.036\right.$ and $\widetilde{T W H}_{2019}^{(w)}-$ $\widetilde{T W H}_{2019}^{(m)}=0.041$ ), indicating that activity-level happiness increased modestly for women relative to men.

Therefore, we estimate that $84.8 \%$ of the increasing gender gap in time-weighted happiness was driven by a more favourable trend in the allocation of time for women compared to men (since $(0.013-$ $(-) 0.015) /(0.055-0.022)=0.848) .{ }^{8}$ A caveat to these findings is that our happiness estimates are based on data from four distinct years, i.e., 1985, 2010, 2012, and 2013. We interpolate/extrapolate happiness estimates in all other years. Given that time-weighted happiness exhibits considerable changes around the recession period, ${ }^{9}$ one should interpret changes in time-weighted happiness after 2013 with caution. In particular, macroeconomic conditions have improved between 2013 and 2019. Thus, our imputed happiness estimates for years 2014-2019 may understate actual happiness levels.

\subsection{Subgroup Analysis of Historical Trends in Time-Weighted Happiness}

The previous sections showed marked differences in trends in time-weighted happiness across genders. We now explore whether aggregate trends by gender mask heterogeneity across sub-demographic groups. Specifically, Figure 5 presents trends in time-weighted happiness for four subgroups defined by education, household income, marital status, and employment status.

Starting with the top-left panel of Figure 5, we see, to our surprise, that low-educated individuals always displayed higher time-weighted happiness than high-educated individuals. The gap between these groups even increased across the years, with improvements in time-weighted happiness being most pronounced among low-educated women.

The top-right panel shows levels and patterns of time-weighted happiness across income groups. As expected, men with above-median household income had greater time-weighted happiness than men with below-median income in 1985. However, women with above-median income had lower time-weighted happiness than women with below-median income in 1985. Surprisingly, since 1985, time-weighted happiness rose substantially for below-median income individuals, relative to those with higher income. Consequently, below-median income men are now enjoying greater time-weighted happiness than richer men, and below-median income women are the group with the highest level of time-weighted happiness.

This result contrasts sharply with the previous literature, which documents a strong positive effect of incomes on mental health, happiness, and life satisfaction across and within persons (Gardner \& Oswald, 2007; Layard et al., 2008; Vendrik 2013; Jebb et al., 2018; Kaiser, 2020). However, our results do agree with Kushlev et al., (2015) and Stone et al., (2018) who also use ATUS data on happiness.

The bottom-left panel examines trends in time-weighted happiness among married and unmarried men and women. In 1985, married men were happier than single men, while single women were happier than married women. Since then, married people, relative to singles, gained time-weighted happiness, especially so among women. As a result, married women enjoy much more time-weighted happiness than any other group today. This indicates that the overall rise in women's time-weighted happiness we observed in Figure 3 was primarily driven by married women. These results are largely in line with previous work on the relationship between marriage and subjective wellbeing (Blanchflower \& Oswald, 2004b; Clark \& Georgellis, 2013).

\footnotetext{
${ }^{8}$ In Appendix Figure 7, we examine the relative contribution of each activity to these gendered trends. We find that the contribution of travel and out-of-home leisure (in-home leisure) to women's time-weighted happiness substantially improved (declined) over time.

${ }^{9}$ Happiness levels were substantially higher in 2012-13 than in 2010, the period immediately following the Great Recession. Thus, recessions appear important for how much people enjoy their time. This is consistent with De Neve et al.'s (2018) findings.
} 
Figure 5. Time-weighted happiness across four population subgroups.
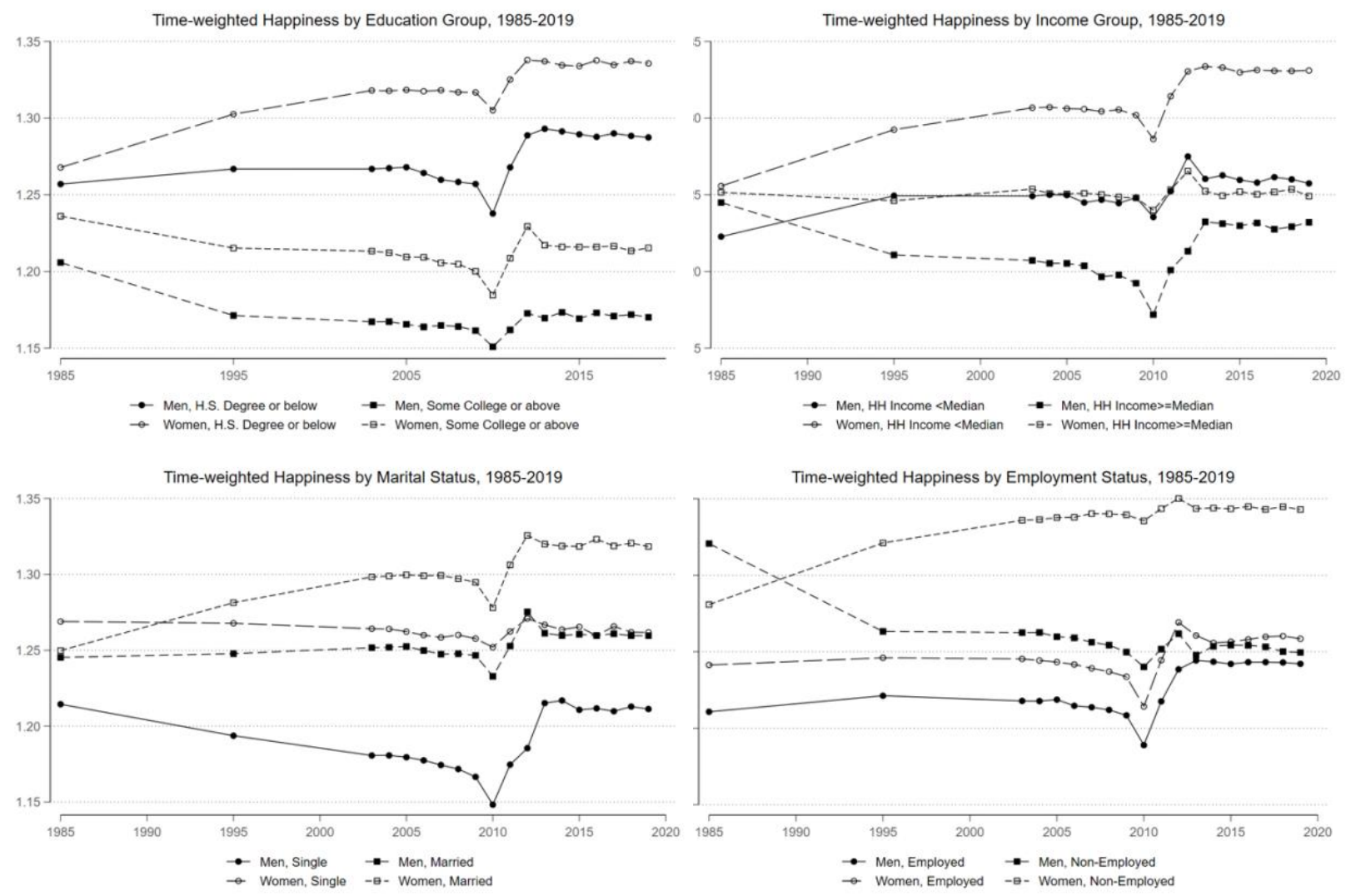

Note: This figure plots changes in the aggregate happiness by gender and education (top-left), income (top-right), marital status (bottom-left), and employment status (bottom-right). FE-adjusted happiness estimates are based on data from 1985, 2010, 2012, and 2013. Happiness estimates in all other years are interpolated or extrapolated as described in note to Figure 3. Estimates are weighted using fixed demographic weights.

Finally, in the bottom-right panel we compare levels and changes in time-weighted happiness between the employed and the non-employed. Previous studies find mixed evidence on the effect of employment on time-weighted happiness using German, UK, and US data (Knabe et al. 2010; Dolan et al., 2017; Hoang \& Knabe, 2020). We find that men and women who are not working tend to be happier than those in work. Nevertheless, non-employed men, compared to employed men, experienced a dramatic decline in happiness between 1985 and 2019, leading to a convergence in happiness between the employed and non-employed in 2019. This contrasts with non-employed women who experienced a rise in time-weighted happiness relative to the employed. Consequently, non-employed women's time-weighted happiness is the greatest among the four groups in 2019.

To further analyse these findings, Appendix Figure 8 shows levels and changes in FE-adjusted happiness and time-use across each of these subgroups. When comparing above-median income individuals or highlyeducated individuals with people with below-median incomes or low education, we see that both the relative enjoyability of leisure and time spent on leisure fell for the more advantaged groups. This suggests that time pressure increased for high-income and highly educated individuals (Hamermesh and Lee, 2007). Moreover, when comparing the employed and the non-employed, we find that non-employed men spend relatively more time watching TV, despite the fact that the relative enjoyability of watching TV fell. By contrast, for non-employed women, both the enjoyability of watching TV and how much time is spent on 
it increased. These patterns explain the substantial fall (rise) in time-weighted happiness for non-employed men (women) relative to employed men (women) in Figure 5.

To formally quantify the relative importance of changes in happiness relative to changes in time-use to trends in time-weighted happiness, we conduct a decomposition analysis in Appendix Figure 9, which is analogous to the one shown in Figure 4. These results suggest that the differential trends in time-weighted happiness across subgroups are largely driven by relative changes in the extent to which individual activities produce happiness, and less by relative changes in time allocation.

\subsection{Comparing Life Satisfaction and Time-Weighted Happiness.}

Our results, particularly regarding the diverging trend in male vs female happiness, the ranking of happiness levels among those working vs. non-working, and among those with low vs. high incomes, are in stark contrast to earlier papers. This may be explained by differences in measures of happiness. Most work on self-reported wellbeing uses a coarse measure, where individuals are asked to globally aggregate their mental lives across both time and activities. ${ }^{10}$ Previous research shows that people are systematically biased in such aggregations. For example, compared to peaks and troughs, individuals tend to underweight periods with medium intensity levels, and overweight feelings at the end of a given period (Kahnemann 1999). In contrast, in our data, people only make a subjective reconstruction of how much they enjoyed each activity in a day, while over-time aggregation is done on an objective basis.

Luckily, the 2012-13 ATUS include data on both life satisfaction (in which people subjectively aggregate over time), and activity-level happiness data. It is thus possible to compare these measures in this period.

We first regress life satisfaction on two measures of happiness. The first measure is given by the estimated individual fixed effect $\widehat{\theta}_{i t}$ obtained from estimating equation (1) on the original seven-point happiness scale. This coefficient captures the total variation in reported activity-level happiness explained by individual characteristics that do not vary across activities. The coefficient thus either reflects individuals' underlying happiness level on the diary day or idiosyncrasies in scale use. The second measure records time-weighted happiness based on each individual's reported activity-level happiness and time allocation, i.e.:

$$
T W H_{i}=\sum_{j} h_{i j} \frac{\text { time }_{i j}}{\text { total time }_{i}}
$$

This time-weighted happiness measure is an individual-level analogue to the groups-based measure of equation (2). Unlike the happiness fixed effect, which is insensitive to the amount of time allocated on different activities, this measure is sensitive to both time-allocation and differences in the enjoyability of individual activities.

To ease comparability across measures, we normalize life satisfaction and both happiness measures into zscores with mean zero and unit standard deviation.

Column 1 in Table 1 reports the coefficients from regressing life satisfaction on the happiness fixed effect. As we should expect, the happiness fixed effect is positively associated with life satisfaction and explains $14 \%$ of the variation in life satisfaction, implying a Pearson's correlation of $\sqrt{0.14}=0.37$. Column 2 reports results from regressing life satisfaction on time-weighted happiness. We again obtain a positive regression coefficient but explain slightly less variation in life satisfaction $\left(r^{2}=0.12\right.$, i.e., a correlation of 0.35). The relationship between life satisfaction and happiness measures are largely unchanged when additionally including demographic characteristics and day of week, month, and year (columns 3 and 4).

\footnotetext{
${ }^{10}$ For example, when responding to the questions "How happy are you these days?" or "Taking all things together, how satisfied are you with your life?" (posed in the American GSS and German SOEP), respondents must aggregate across time (e.g. the last few days), and across domains (e.g. family life, health, one's job).
} 
Table 1. Relationship between Life Satisfaction and Time-weighted Estimated Happiness, ATUS 2012-2013

\begin{tabular}{|c|c|c|c|c|c|}
\hline Dependent Variable & \multicolumn{5}{|c|}{ Life Satisfaction } \\
\hline $\mathrm{Z}$ (Happiness based on Individual FE) & $\begin{array}{c}0.765 * * * \\
(0.022)\end{array}$ & & $\begin{array}{c}0.746 * * * \\
(0.021)\end{array}$ & & $\begin{array}{c}0.763 * * * \\
(0.058)\end{array}$ \\
\hline $\mathrm{Z}$ (Happiness based on time-use) & & $\begin{array}{c}0.713 * * * \\
(0.022)\end{array}$ & & $\begin{array}{c}0.690 * * * \\
(0.022)\end{array}$ & $\begin{array}{c}-0.018 \\
(0.058)\end{array}$ \\
\hline Control for Demogr. Characteristics, Diary Times & No & No & Yes & Yes & Yes \\
\hline R-squared & 0.140 & 0.123 & 0.192 & 0.174 & 0.192 \\
\hline Mean of Dep. Var. & & & 7.123 & & \\
\hline Number of Observations & & & 19,770 & & \\
\hline
\end{tabular}

Note: The table reports estimates from regressions of general life satisfaction, ranging from 0 (worst possible life) 10 (best possible life), on happiness estimates based on individual FE and/or time-use. "Happiness based on individual FE" is measured as the coefficient on individual fixed effects from estimating equation (1). Happiness based on time-use is measured as shown in equation (3). Values of these two happiness measures are normalized with mean zero and standard deviation of one. Demographic characteristics include age, sex, marital status, education level, number of adults, number of children in the household, and diary times including diary month, year, and day of week. Estimates are weighted using fixed demographic weights.

When including both happiness measures in the specification, the coefficient on the happiness fixed effect remains largely unchanged. However, the coefficient on individual-level time-weighted happiness becomes insignificant and close to zero (column 5). This indicates that time-weighted happiness is mostly unrelated to life satisfaction once individuals' underlying happiness levels are accounted for.

In turn, this suggests that time-weighted happiness is an aspect of wellbeing that is largely separate from more standard measures. Previous work showed that standard measures of life satisfaction and affect are positively correlated. For example, Kahneman et al. (2010) and Luhmann et al. (2012), respectively, found a correlation of 0.36 and 0.33 between affect and life satisfaction. Our analyses show that these correlations reflect associations between life satisfaction and stable person-specific characteristics (e.g., personality traits), rather than an association between life satisfaction and time-weighted happiness. ${ }^{11}$

Given these results, a key question is whether the correlates of time-weighted happiness and life satisfaction also differ. Our second analysis, reported in Table 2, investigates this question. There, we estimate OLS regressions of life satisfaction and of individual time-weighted happiness (i.e., the same measures as shown in columns 2 and 4 of Table 1), on a set of standard socio-economic characteristics. These characteristics include gender, marital status, education, income, employment status, age, household composition, and day of interview.

Since the 2012-2013 data contains information on life satisfaction and offers a much larger sample, we begin with this period (columns 2-3 and 5-6). Concerning life satisfaction, columns 3 and 6 reproduce several standard results: Those who are married, who have children, and who are employed tend to be more satisfied with their lives. Moreover, consistent with previous results by Hamermesh (2020), higher incomes are associated with greater life satisfaction, and that association does not level off at higher income levels. Finally, as indicated by the negative coefficient on age and the positive coefficient on age-squared, life satisfaction is a u-shaped function of age. These results hold for both men and women, though coefficients are typically larger for men than for women.

When considering time-weighted happiness, we again observe that those who are married, with children, and those who are employed are happier. We also reproduce the u-shape in age. However, these associations are much less pronounced. Most strikingly, we find no clear association between income and time-weighted happiness. Indeed, the coefficients on being in the fourth quartile of the income distribution are even

\footnotetext{
${ }^{11}$ This is also in line with Berlin and Conolly (2019) who estimate a correlation of 0.78-0.91 between measures of life satisfaction and affect that are both purged of transitory components.
} 
Table 2. Relationships between Life Satisfaction or Happiness and Socio-economic Characteristics, 1985 and 2012-13

\begin{tabular}{|c|c|c|c|c|c|c|}
\hline \multirow{3}{*}{$\begin{array}{l}\text { Year } \\
\text { Wellbeing } \\
\text { measure }\end{array}$} & \multicolumn{3}{|c|}{ Men } & \multicolumn{3}{|c|}{ Women } \\
\hline & 1985 & \multicolumn{2}{|c|}{$2012-13$} & 1985 & \multicolumn{2}{|c|}{$2012-13$} \\
\hline & $\begin{array}{c}\text { Time- } \\
\text { weighted } \\
\text { happiness }\end{array}$ & $\begin{array}{c}\text { Time- } \\
\text { weighted } \\
\text { happiness }\end{array}$ & $\begin{array}{c}\text { Life } \\
\text { satisfaction }\end{array}$ & $\begin{array}{c}\text { Time- } \\
\text { weighted } \\
\text { happiness }\end{array}$ & $\begin{array}{c}\text { Time- } \\
\text { weighted } \\
\text { happiness }\end{array}$ & $\begin{array}{c}\text { Life } \\
\text { satisfaction }\end{array}$ \\
\hline \multirow[t]{2}{*}{ Married } & 0.026 & $0.165 * * *$ & $0.236 * * *$ & -0.012 & $0.148 * * *$ & $0.303 * * *$ \\
\hline & (0.103) & $(0.033)$ & $(0.033)$ & $(0.077)$ & $(0.027)$ & $(0.028)$ \\
\hline \multirow[t]{2}{*}{ Age } & 0.001 & $-0.022 * * *$ & $-0.031 * * *$ & -0.009 & $-0.009 * *$ & $-0.018 * * *$ \\
\hline & $(0.016)$ & $(0.005)$ & $(0.005)$ & $(0.012)$ & $(0.005)$ & $(0.005)$ \\
\hline \multirow[t]{2}{*}{$\mathrm{Age}^{2}$} & 0.000 & $0.000 * * *$ & $0.000 * * *$ & 0.000 & $0.000 * * *$ & $0.000 * * *$ \\
\hline & $(0.000)$ & $(0.000)$ & $(0.000)$ & $(0.000)$ & $(0.000)$ & $(0.000)$ \\
\hline \multirow[t]{2}{*}{ Have children } & $-0.175^{*}$ & $0.075 * *$ & $0.080 * *$ & -0.079 & $0.102 * * *$ & 0.038 \\
\hline & $(0.093)$ & $(0.034)$ & $(0.034)$ & $(0.077)$ & $(0.030)$ & $(0.030)$ \\
\hline \multirow[t]{2}{*}{ Some college+ } & -0.118 & $-0.124 * * *$ & 0.000 & -0.102 & $-0.091 * * *$ & $-0.082 * * *$ \\
\hline & $(0.082)$ & $(0.032)$ & $(0.030)$ & $(0.071)$ & $(0.029)$ & $(0.029)$ \\
\hline \multirow[t]{2}{*}{$2^{\text {nd }}$ inc. quart. } & -0.011 & -0.006 & 0.051 & 0.013 & 0.001 & $0.127 * * *$ \\
\hline & (0.124) & $(0.046)$ & $(0.046)$ & $(0.102)$ & $(0.036)$ & $(0.037)$ \\
\hline \multirow[t]{2}{*}{$3^{\text {rd inc. quart. }}$} & 0.180 & 0.014 & $0.086^{*}$ & 0.109 & 0.017 & $0.184 * * *$ \\
\hline & $(0.129)$ & $(0.044)$ & $(0.044)$ & $(0.111)$ & $(0.037)$ & $(0.039)$ \\
\hline \multirow[t]{2}{*}{$4^{\text {th }}$ inc. quart. } & 0.064 & -0.026 & $0.287 * * *$ & 0.097 & -0.070 & $0.318 * * *$ \\
\hline & $(0.126)$ & $(0.050)$ & $(0.051)$ & (0.109) & $(0.044)$ & $(0.043)$ \\
\hline \multirow[t]{2}{*}{ Employed } & -0.057 & 0.070 & $0.263 * * *$ & 0.026 & 0.034 & $0.096 * * *$ \\
\hline & $(0.158)$ & $(0.049)$ & $(0.055)$ & $(0.087)$ & $(0.034)$ & $(0.036)$ \\
\hline \multirow[t]{2}{*}{ Unemployed } & $0.448^{*}$ & 0.096 & $-0.160 *$ & 0.031 & 0.046 & $-0.185^{* *}$ \\
\hline & $(0.239)$ & $(0.075)$ & $(0.084)$ & $(0.126)$ & $(0.062)$ & $(0.074)$ \\
\hline \multirow[t]{2}{*}{ Retired } & 0.276 & -0.058 & $0.238 * * *$ & $0.318 *$ & 0.063 & $0.257 * * *$ \\
\hline & $(0.204)$ & $(0.066)$ & $(0.064)$ & $(0.169)$ & $(0.049)$ & $(0.052)$ \\
\hline Interview times & Yes & Yes & Yes & Yes & Yes & Yes \\
\hline R-squared & 0.070 & 0.024 & 0.065 & 0.058 & 0.018 & 0.061 \\
\hline \# Observations & 1,029 & 8,732 & 8,749 & 1,238 & 11,038 & 11,057 \\
\hline
\end{tabular}

Note: Life satisfaction and happiness measures are normalized with mean zero and standard deviation of one. Interview times include interview month and year. Estimates are weighted using survey weights.

negative for both men and women. ${ }^{12}$ Hence, although higher incomes increase life satisfaction, they do not increase happiness when objectively weighting over time. Furthermore, we find that unemployment, albeit insignificant, is associated with greater time-weighted happiness for both genders. Though these results do not agree with Krueger \& Mueller (2012), who find that the unemployed report more sadness, these results do agree with the results by Knabe et al. (2010) concerning Germany, results by Dolan et al. (2017) and Hoang \& Knabe (2020: 2021) concerning the United Kingdom and United States, as well as results by Flèche \& Smith (2017) for France. Unfortunately, given the small sample sizes available in the 1985 data, estimates are less precise for this time-period (see columns 1 and 4). It is nevertheless noteworthy that, among men, the coefficient on being unemployed is large, positive, and statistically significant. For women, this coefficient is positive, too, but smaller and statistically insignificant. Indeed, most other coefficients are also insignificant for our 1985 data.

\section{Robustness Tests}

Our baseline estimations assume that the distribution of our 3-point common happiness measure is stable across surveys and that distances between any given two values are equal. One might be worried that our results may change substantially when relaxing these assumptions. We therefore examine the extent to which alternative assumptions affect our estimates.

\footnotetext{
${ }^{12}$ Appendix Figure 17 plots the relationship between income, time-weighted happiness, and life satisfaction nonparametrically. Again, we find no association between income and time-weighted happiness and a clearly positive association between income and life satisfaction (with decreasing marginal returns).
} 


\subsection{Impact of Alternative Scale-Use Assumptions on Estimates of Historical Trends}

To see if our result of an increasing gender gap depends on our harmonization of the happiness data, we first estimate ordered probit regressions. Here, we assume that error $\epsilon_{i j}$ in equation (1) is normally distributed with mean zero and standard deviation 1 , and that $h_{i j t}$ relates to the reported data as $r_{i j}=k \leftrightarrow$ $\tau_{t, k}<h_{i j t} \leq \tau_{t, k}$, where $r_{i j t}$ is the level of happiness reported on the original year-specific scales.

We further assume that $\tau_{1985,8}=\tau_{t \leq 2010,5}=0$. Substantively, this means that we assume that the threshold for reporting an 8 out of 10 in 1985 is the same as reporting a 5 out of 6 in the 2010s. This assumption is weaker than the assumptions we adopted in our main analysis, as it only requires one threshold in the happiness scale to be equal across surveys. ${ }^{13}$ Setting these thresholds to zero is arbitrary; any other value would have served equally well.

Since an ordered probit fixed effects estimator is not directly available, we include demeaned individual averages of each activity indicator as controls in our estimation. Individual averages are given by $\overline{A c t}_{i j}=$ $\mathbb{1}\{\text { Activity }=j\}_{i} / J_{i}$. Demeaned individual averages are then given by $\ddot{A c t} t_{i j}=\overline{A c t}_{i j}-\overline{\overline{A c t}}_{j}$ where $\overline{\overline{A c t}}_{j}$ is the average of $\overline{A c t}_{i j}$ across all respondents $i$. We thus estimate:

$$
h_{i j}=\sum_{j}^{J_{i}} \beta_{j t}^{(g)} \mathbb{1}\{\text { Activity }=j\}_{i}+\gamma_{j t}^{(g)} \ddot{A c} t_{i j}+\varepsilon_{i j}
$$

As shown by Van Praag (2015), this yields estimates that are equivalent to a fixed effects regression. The estimates of equation (3) are then used as inputs to equation (2) to obtain trends in time-weighted happiness.

Figure 6 shows our results. Unlike the results in Figure 3, we now see a positive trend for both genders. Nevertheless, we again observe that the gender gap in time-weighted happiness has been markedly increasing since 1985. Therefore, our key finding that women's time-weighted happiness has increased relative to men's is robust to using either OLS or ordered probit regressions. The overall more positive trend of Figure 6 is driven by our assumption that the $8^{\text {th }}$ threshold on the 1985 scale has the same location as the $5^{\text {th }}$ threshold $2010 \mathrm{~s}$ scale. If we had made the (implausible) assumption that, say, the $2^{\text {nd }}$ threshold on the 1985 scale was equivalent to the $8^{\text {th }}$ threshold of the 2010s scale, we would have observed an overall negative trend in time-weighted happiness. Importantly however, the differences in trends between men and women are not driven by this normalization.

As another robustness test, we return to using OLS fixed-effects estimations. Instead of using the 3-point common happiness scale, we now dichotomize the 1985 and the 2010s happiness scales in six different ways. Specifically, for each dichotomization of the original 7-point happiness scale in 2010s, we collapse the 11-point happiness scale in 1985 into two categories such that the distribution of the dichotomized happiness scale remains stable over time. Appendix Figure 11 shows our results when using each of these binary variables. Our finding that women have gained relative to men is observed in each case. However,

\footnotetext{
${ }^{13}$ In section 3, we made the stronger assumption that $h_{i j t}=0$ for both $r_{i j, 1985} \leq 2$ and $r_{i j, t \leq 2010} \leq 1, h_{i j t}=1$ for both $2<r_{i j, 1985} \leq 8$ and $1<r_{i j, t \leq 2010} \leq 5$, and $h_{i j t}=2$ for both $8 \geq r_{i j, 1985}$ and $5 \geq r_{i j, t \leq 2010}$.
} 
Figure 6. Time-weighted happiness by gender using ordered probit, 1985-2019.

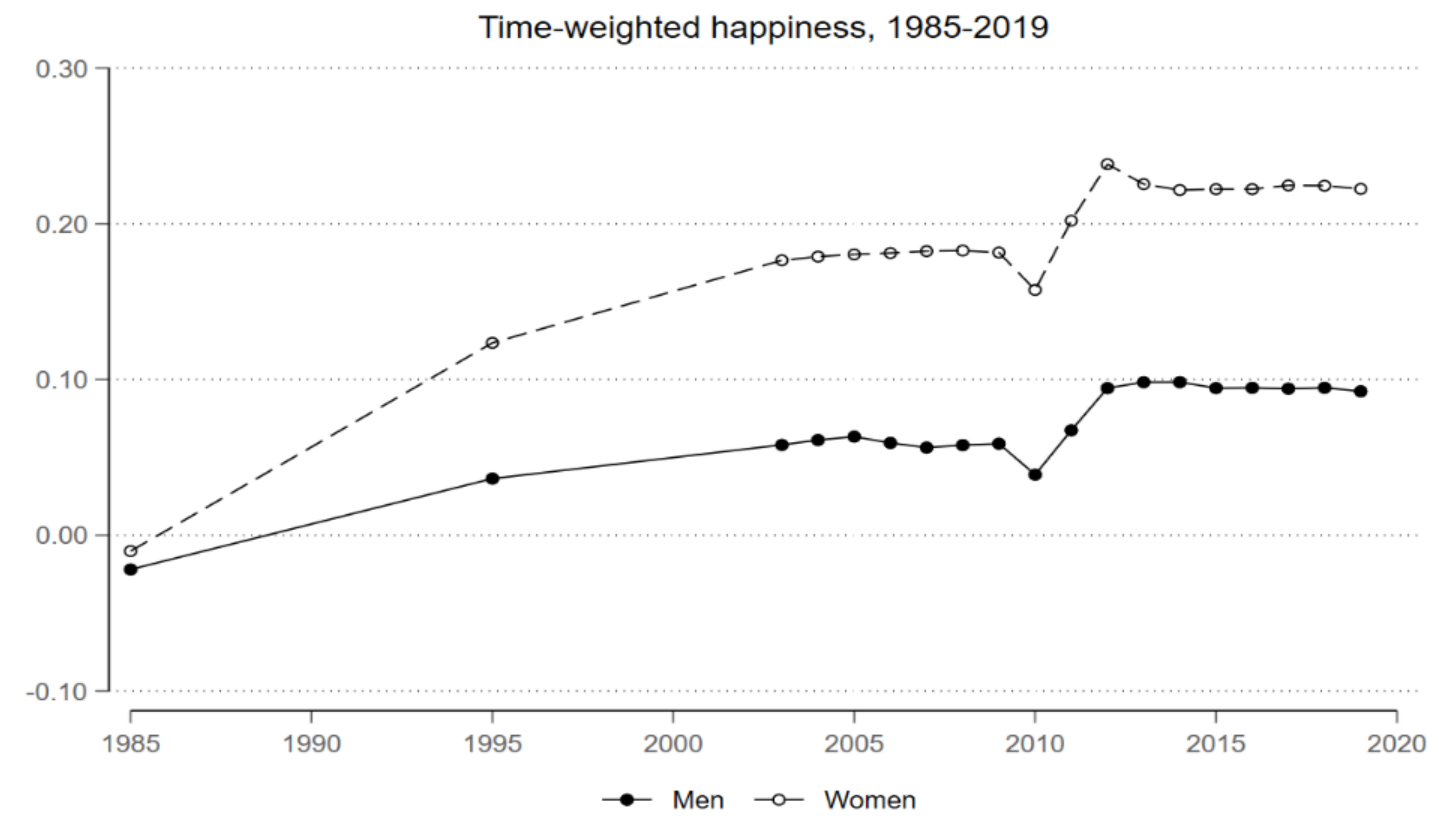

Note: Trends in time-weighted happiness between 1985 and 2019 as estimated via ordered probit regressions.

the size of women's relative gains depends on the chosen dichotomization. For example, when dichotomizing the original 2010-2013 scale at the bottom category (0 vs 1-6) and dichotomizing the original 1985 scale between $0-1$ and 2-10, we only see a small gain for women relative to men (panel A of Appendix Figure 11). When instead dichotomizing between 0-4 and 5-6 on the 2010-2013 scale, and between 0-6 and 7-10 on the 1985 scale, we observe a much bigger gain (panel E of Appendix Figure 11). These results therefore show that although women have become happier than men across the entire happiness distribution their gains were largest in the middle of the distribution.

Finally, we evaluate the robustness of results to using a common 4-point happiness scale, instead of a 3point scale. We again collapse the original scales such that the distribution of the common 4-point scale is stable across surveys. Appendix Figure 15 shows the increasing gender gap is even more apparent with this measure $\left(T W H_{1985}^{(w)}-T W H_{1985}^{(m)}=0.012, p=0.348 ; T W H_{2019}^{(w)}-T W H_{2019}^{(m)}=0.092, p=0.003\right)$, indicating that the our key finding is not sensitive to our choice of how happiness scales are collapsed over time.

\subsection{Impact of Alternative Scale-Use Assumptions on Determinants of Life Satisfaction and Time- Weighted Happiness}

Like our historical trends, estimates of the determinants of life satisfaction and time-weighted happiness might depend on treating our measures as cardinal. As shown by Schröder and Yitzhaki (2017) and Bond and Lang (2019), coefficient signs in regressions of ordinal happiness data may be impacted by positive monotonic transformations of reported happiness.

To address this concern, we rerun the regressions of Table 2 for every possible dichotomization of our life satisfaction and happiness variables. In particular, we first construct a set of binary life satisfaction variables $d_{i j}^{(k)}=\mathbb{1}\left\{h_{i j}>k\right\}$ for all $k \in\{1,2, \ldots, 9\}$ and in turn regress them on the same characteristics as in Table 2. We proceed analogously for time-weighted happiness. As shown in Kaiser \& Vendrik (2020) and explained 
in Appendix B, if a variable's estimated coefficient has the same sign across all dichotomisations, there exist no monotonic transformation of reported happiness that leads to a reversal of that coefficient's sign.

Appendix Table 3 shows that the positive associations of life satisfaction with being married and being retired cannot be reversed by any transformation. The u-shaped association with age cannot be reversed either. For men only, the positive association with being employed is similarly robust. However, our results are not as robust for having children, for having a college education, for income, and for unemployment. In particular, both having a college education, and being at the $2^{\text {nd }}$ income quartile, increases the probability of reporting $d_{i}^{(k)}=1$ for $k \leq 6$, but lowers the probability of reporting $d_{i}^{(k)}=1$ for $k>6$. Similarly, being unemployed (and having children) increases the probability of reporting $d_{i}^{(k)}=1$ for $k \leq 4(k \leq 1)$ but lowers the probability of reporting $d_{i}^{(k)}=1$ for $k>4(k>1)$. An analogous pattern occurs for employment among women. We find similar results for time-weighted happiness. One substantive difference there, is that the association with having children has the same sign across all dichotomisations and is thus robust.

Substantively, our results imply that income, education, and unemployment increase wellbeing (in terms of both happiness and life satisfaction) at the lower end of the scale but decrease wellbeing at the top. Thus, if we were to maintain the assumption that happiness and life satisfaction are measured cardinally, increases in each of these explanatory variables decrease inequality in wellbeing. In contrast, if we reject the assumption of cardinality, the results imply that monotonic transformation of happiness and life satisfaction exist that would reverse the coefficients we obtained in Table 2. However, as shown in Appendix B, the transformations required for such reversals are typically too extreme to be plausible.

\subsection{Time-Trends and Determinants of Time-Weighted Happiness in the UK}

Are our results specific to the United States, or are they more widely applicable? While a number of countries have collected time-use surveys for an extended period, the United Kingdom is, to our knowledge, the only other country that collected wellbeing data at the episode level in the 1980s. In particular, the "Unilever Market Research Survey" and the "UK Time-Use Survey" (UKTUS) respectively collected timeuse and happiness data in 1986 and 2014-2015.

However, the 1986 survey was conducted in June and July only and is based on a non-representative sample of UK population. We nevertheless use the UK datasets by restricting the sample of the 2014-15 data to June and July. Applying the estimation procedures used for our baseline analysis to the UK data (see equations (1) and (2) in sections 2.3 and 3.2), we estimate trends in time-weighted happiness by gender in the UK. ${ }^{14}$

As shown in Appendix Figure 12, there are several differences in activity-level happiness and time allocation between the US and the UK. For example, happiness from social care remains stable in the UK, while it has become more pleasant in the US. Moreover, in the UK, happiness from watching TV remained stable for men and increased for women. In contrast, in the US, happiness from watching TV has declined for both genders. However, some other activities exhibit similar trends in happiness in both countries. For example, happiness during domestic work and shopping, perhaps driven by common technological improvements, has improved over in both countries. Furthermore, just like in the US, how much time people spend on individual activities appears to be uncorrelated with the amount of happiness they derive from these activities, as shown in Appendix Figure 13.

\footnotetext{
${ }^{14}$ The UK surveys from 1986 and 2014-15 use different response scales. We again convert the original response scales to a common 3-point scale such that the distribution of rescaled happiness remains stable over time. Also, we apply our fixed demographic weights to the UK samples, so that the demographic composition of the UK samples matches that of the US in 1985.
} 
Moreover, despite the subtle differences at the level of individual activities across the US and UK, Appendix Figure 14 shows a similar trend in the gender gap in time-weighted happiness: while women's timeweighted happiness has remained largely stable since 1986, men's time-weighted happiness has significantly fallen since 1986 , leading to a much increased gender gap in 2014-15 $\left(\Delta T W H_{1986}^{(w-m)}=\right.$ $\left.0.035 ; p=0.163 ; \Delta T W H_{2014-15}^{(w-m)}=0.101 ; p=0.034\right)$.

Finally, in Appendix Tables 5 and 6, we respectively reproduce Tables 1 and 2 using 2014-2015 UK data. The amount of variance in life satisfaction explained by a person's happiness fixed effect, or that person's time-weighted happiness is even lower than was the case for the US $\left(r^{2}=0.069\right.$ and $r^{2}=0.053$, respectively). As in the US, once we enter both a person's happiness fixed effect and their time-weighted happiness, the latter variable does not enter the regression significantly (Appendix Table 5). Similarly, our results for the determinants of happiness and life satisfaction match those for the US (Appendix Table 6).

\section{Conclusion}

There has been growing interests in developing a comprehensive measure of national wellbeing that goes beyond economic resources (Stiglitz et al., 2009). In that vein, a growing literature focused on measuring subjective wellbeing by asking people to globally evaluate their life in response to a single question. Answering such a question accurately is challenging because it involves significant cognitive efforts to aggregate one's feelings and judgements about one's life across both time and activities (Kahnemann 1999; Fleurbaey \& Blanchet 2013; Benjamin et al. 2020). Answers to global life satisfaction question may therefore be prone to cognitive biases.

To meet this challenge, we use national time-use surveys to document how people's hourly (i.e., activitylevel) affective experiences have changed over the last three decades. We find that happiness during domestic work, shopping, travel, and social care rose substantially between 1985 and 2013. These changes may reflect technological advances. By contrast, happiness during watching TV declined during the same period, which may reflect improved opportunities for other types of leisure activities.

We then construct a measure of aggregate daily happiness by weighting activity-level happiness by time allocation. Previous studies that relied on a global and evaluative measure of happiness found that men's time-weighted happiness rose relative to women's happiness since 1970s, which has been considered a "paradox" because various objective wellbeing indicators suggest otherwise (Stevenson and Wolfers, 2009). Our results using time-weighted happiness indicate that men's time-weighted happiness declined relative to women's happiness over the last three decades, which is largely due to unfavourable shifts in time allocation for men relative to women. Importantly, we demonstrate that our results are not sensitive to assumptions about how people use happiness scales, and we find the similar trends using UK data.

Our subgroup analyses reveal that time-weighted happiness for individuals with low-income has improved over the last 35 years relative to those with high-income. This result implies that a measure of wellbeing that incorporates both time-weighted happiness and income is likely to indicate a less divergent trend in inequality relative to a measure that is based on income alone.

To better understand how time-weighted happiness differ from other global subjective wellbeing measures, we examined the relationship between global life satisfaction and time-weighted happiness, as well as the association between time-weighted happiness and various demographic characteristics. These analyses indicate that most of the variation in global life satisfaction across individuals does not reflect differences in time-weighted happiness. Moreover, individual characteristics such as income and employment are positively correlated with life satisfaction but have no or negative association with time-weighted happiness. Thus, activity-level happiness appears to be an aspect of wellbeing that is fundamentally distinct from more traditional measures. Therefore, policymakers may face a trade-off between improving time-weighted happiness and improving life satisfaction. For example, increasing incomes seems much more promising from life satisfaction perspective, than from a time-weighted happiness perspective 
We see three fruitful avenues for future research. First, whether the happiness gender gap that exists in the US and UK can also be observed in other countries should be investigated. A key question then concerns the determinants of this gap, including incomes, technology, or gender roles. Second, the lack of correlation between the degree to which activities are enjoyable and how much time people allocate to each activity is counterintuitive and needs further explanation. Third, a more comprehensive investigation of the differences and similarities in the determinants of time-weighted happiness vs life satisfaction is needed. Such an effort should particularly disentangle the contributions of time-allocation and overall changes in happiness in determining time-weighted happiness. Finally, given that life satisfaction and time-weighted happiness do not show the same trends and determinants, it is key to evaluate which of these measures matters more. Recent work by Benjamin et al. (2014), who quantified how individuals values different aspects of wellbeing is one welcome step in that direction. 


\section{References}

Aguiar, Mark, and Erik Hurst. "Measuring trends in leisure: The allocation of time over five decades." The Quarterly Journal of Economics 122, no. 3 (2007): 969-1006.

Berlin, Martin, and Filip Fors Connolly. "The association between life satisfaction and affective wellbeing." Journal of Economic Psychology 73 (2019): 34-51.

Blanchflower, David G., and Andrew J. Oswald. "Well-being over time in Britain and the USA." Journal of public economics 88, no. 7-8 (2004a): 1359-1386.

Blanchflower, David G., and Andrew J. Oswald. "Money, sex and happiness: An empirical study." Scandinavian Journal of Economics 106, no. 3 (2004b): 393-415.

Benjamin, D. J., Heffetz, O., Kimball, M. S., \& Szembrot, N. "Beyond happiness and satisfaction: Toward well-being indices based on stated preference." American Economic Review, 104, no. 9 (2014): 2698-2735.

Benjamin, D. J., Guzman, J.K., Heffetz, O., Fleurbaey, M., Kimball, M. S. "What Do Happiness Data Mean? Theory and Survey Evidence". Working Paper (2020).

Bond, Timothy N., and Kevin Lang. "The sad truth about happiness scales." Journal of Political Economy 127, no. 4 (2019): 1629-1640.

Bonke, Jens. "Distribution of economic resources: implications of including household production." Review of Income and wealth 38, no. 3 (1992): 281-293.

Bryant, W. Keith, and Cathleen D. Zick. "Income distribution implications of rural household production." American Journal of Agricultural Economics 67, no. 5 (1985): 1100-1104.

Clark, Andrew E., and Yannis Georgellis. "Back to baseline in Britain: adaptation in the British household panel survey." Economica 80, no. 319 (2013): 496-512.

Cox, Nicholas. 2016. "MIPOLATE: Stata module to interpolate values," Statistical Software Components S458070, Boston College Department of Economics.

Crawford, Duane W., and Geoffrey Godbey. "Reconceptualizing barriers to family leisure." Leisure sciences 9, no. 2 (1987): 119-127.

De Neve, J. E., Ward, G., De Keulenaer, F., Van Landeghem, B., Kavetsos, G., \& Norton, M. I. "The asymmetric experience of positive and negative economic growth: Global evidence using subjective wellbeing data." Review of Economics and Statistics 100, no. 2 (2018): 362-375.

Dolan, P., Kudrna, L., \& Stone, A. "The measure matters: An investigation of evaluative and experiencebased measures of wellbeing in time-use data." Social Indicators Research 134, no. 1 (2017): 57-73.

Fabian, Mark. "Scale Norming Undermines the Use of Life Satisfaction Scale Data for Welfare Analysis." SocArXiv Working Paper. (2019). doi:10.31235/osf.io/cg8n9.

Fisher, Kimberly, Jonathan Gershuny, Sarah M. Flood, Joan Garcia Roman and Sandra L. Hofferth. American Heritage Time Use Study Extract Builder: Version 1.2 [dataset]. Minneapolis, MN: IPUMS, 2018. https://doi.org/10.18128/D061.V1.2

Flèche, Sarah, and Conal Smith. "Time use surveys and experienced well-being in France and the United States." OECD Statistics Working Paper, no. 07 (2017).

Fleurbaey, Marc, Didier Blanchet. "Beyond GDP: Measuring Welfare and Assessing Sustainability." Oxford University Press (2013).

Frazis, Harley, and Jay Stewart. "How does household production affect measured income inequality?." Journal of Population Economics 24, no. 1 (2011): 3-22. 
Gardner, Jonathan, and Andrew J. Oswald. "Money and mental wellbeing: A longitudinal study of mediumsized lottery wins." Journal of health economics 26, no. 1 (2007): 49-60.

Gershuny, Jonathan. “Time-Use Surveys and the Measurement of National Well-Being”. London: Office of National Statistics. (2011)

Gershuny, Jonathan and Oriel Sullivan. "What We Really Do All Day". Penguin Books Ltd. (2019).

Gimenez-Nadal, Jose Ignacio, and Almudena Sevilla. "Trends in time allocation: A cross-country analysis." European Economic Review 56, no. 6 (2012): 1338-1359.

Hamermesh, Daniel S., and Jungmin Lee. "Stressed out on four continents: Time crunch or yuppie kvetch?." The review of Economics and Statistics 89, no. 2 (2007): 374-383.

Hamermesh, Daniel S. "Life satisfaction, loneliness and togetherness, with an application to Covid-19 lockdowns." Review of Economics of the Household 18 (2020): 983-1000.

Han, Jeehoon, Bruce D. Meyer, and James X. Sullivan. "Inequality in the joint distribution of consumption and time-use." Journal of Public Economics 191 (2020): 104106.

Hoang, Thi Truong An, and Andreas Knabe. "Replication: Emotional well-being and unemploymentEvidence from the American time-use survey." Journal of Economic Psychology 83 (2021): 102363.

Hoang, Thi Truong An, and Andreas Knabe. "Time use, unemployment, and well-being: an empirical analysis using British time-use data." Journal of Happiness Studies (2020): 1-24.

Hofferth, Sandra L., Sarah M. Flood, Matthew Sobek and Daniel Backman. American Time Use Survey Data Extract Builder: Version 2.8 [dataset]. College Park, MD: University of Maryland and Minneapolis, MN: IPUMS (2020).

Hurst, Erik. "Thoughts on "National Time Accounting: The Currency of Life"". In Measuring the Subjective Wellbeing of Nations: National Accounts of Time Use and Wellbeing, ed. Alan B. Krueger, 227-241. Chicago: University of Chicago Press. (2009)

Jebb, Andrew T., Louis Tay, Ed Diener, and Shigehiro Oishi. "Happiness, income satiation and turning points around the world." Nature Human Behaviour 2, no. 1 (2018): 33-38.

Jenkins, Stephen P., and Nigel C. O'Leary. "Household income plus household production: the distribution of extended income in the UK." Review of Income and Wealth 42, no. 4 (1996): 401-419.

Juster, F. Thomas, and Frank P. Stafford. "The allocation of time: Empirical findings, behavioral models, and problems of measurement." Journal of Economic literature 29, no. 2 (1991): 471-522.

Kahneman, Daniel, Peter P. Wakker, and Rakesh Sarin. "Back to Bentham? Explorations of experienced utility." The Quarterly Journal of Economics 112, no. 2 (1997): 375-406.

Kahneman, Daniel. "Objective happiness." Well-being: The foundations of hedonic psychology 1 (1999): $1-23$.

Kahneman, Daniel, Alan B. Krueger, David A. Schkade, Norbert Schwarz, and Arthur A. Stone. "A survey method for characterizing daily life experience: The day reconstruction method." Science 306, no. 5702 (2004): 1776-1780.

Kahneman, Daniel, and Angus Deaton. "High income improves evaluation of life but not emotional wellbeing." Proceedings of the national academy of sciences 107, no. 38 (2010): 16489-16493.

Kaiser, Caspar. "People do not adapt. New analyses of the dynamic effects of own and reference income on life satisfaction." Journal of Economic Behavior \& Organization 177 (2020): 494-513.

Kaiser, Caspar and Maarten C.M. Vendrik, "How Threatening are Transformations of Reported Happiness to Subjective Wellbeing Research?” INET Working Paper, no. 19 (2020). 
Knabe, Andreas, Steffen Rätzel, Ronnie Schöb, and Joachim Weimann. "Dissatisfied with life but having a good day: time-use and well-being of the unemployed." The Economic Journal 120, no. 547 (2010): 867889.

Krueger, Alan B. "Are we having more fun yet? Categorizing and evaluating changes in time allocation." Brookings Papers on Economic Activity 2007, no. 2 (2007): 193-215.

Krueger, Alan B., Daniel Kahneman, David Schkade, Norbert Schwarz, and Arthur A. Stone.. "National Time Accounting: The Currency of Life". In Measuring the Subjective Wellbeing of Nations: National Accounts of Time Use and Wellbeing, ed. Alan B. Krueger, 9-86. Chicago: University of Chicago Press. (2009)

Krueger, Alan B., and Andreas I. Mueller. "Time use, emotional well-being, and unemployment: Evidence from longitudinal data." American Economic Review 102, no. 3 (2012): 594-99.

Kushlev, Kostadin, Elizabeth W. Dunn, and Richard E. Lucas. "Higher income is associated with less daily sadness but not more daily happiness." Social Psychological and Personality Science 6, no. 5 (2015): 483489.

Layard, Richard, Guy Mayraz, and Stephen Nickell. "The marginal utility of income." Journal of Public Economics 92, no. 8-9 (2008): 1846-1857.

Luhmann, Maike, Louise C. Hawkley, Michael Eid, and John T. Cacioppo. "Time frames and the distinction between affective and cognitive well-being." Journal of research in personality 46, no. 4 (2012): 431-441.

Pepin, Joanna R., Liana C. Sayer, and Lynne M. Casper. "Marital Status and Mothers' Time Use: Childcare, Housework, Leisure, and Sleep.” Demography 55, no. 1 (2018): 107-133.

Ramey, Valerie. "How Much has Leisure Really Increased Since 1965?." Working Paper (2007).

Robinson, John, and Geoffrey Godbey. “Time for Life”, University Park, PA: Pennsylvania State University Press (1999).

Sevilla, Almudena, Jose I. Gimenez-Nadal, and Jonathan Gershuny. "Leisure Inequality in the United States: 1965-2003" Demography 49, no. 3 (2012): 939-964.

Schroeder, Carsten, and Shlomo Yitzhaki. "Revisiting the evidence for cardinal treatment of ordinal variables." European Economic Review 92 (2017): 337-358.

Schwarz, Norbert, and Fritz Strack. "Reports of subjective well-being: Judgmental processes and their methodological implications." Well-being: The foundations of hedonic psychology 7 (1999): 61-84.

Stevenson, Betsey, and Justin Wolfers. "The paradox of declining female happiness." American Economic Journal: Economic Policy 1, no. 2 (2009): 190-225.

Stiglitz, Joseph, Amartya Sen, and Jean-Paul Fitoussi. "The measurement of economic performance and social progress revisited: reflections and overview.” Sciences Po Working Paper, no. 33 (2009).

Stone, Arthur A., Stefan Schneider, Alan Krueger, Joseph E. Schwartz, and Angus Deaton. "Experiential wellbeing data from the American Time Use Survey: Comparisons with other methods and analytic illustrations with age and income." Social indicators research 136, no. 1 (2018): 359-378.

Vendrik, Maarten CM. "Adaptation, anticipation and social interaction in happiness: An integrated errorcorrection approach." Journal of Public Economics 105 (2013): 131-149.

Zuzanek, Jiri, and Tamara Zuzanek. "Of Happiness and of Despair, Is There a Measure? Time Use and Subjective Well-being.” Journal of Happiness Studies 16 (2015): 839-856. 


\section{Appendix A. Derivation of Decomposition}

Consider two groups $i \in 1,2$ and some set of activities $j \in 1,2, \ldots, J$. Time-weighted happiness for group $i$, $u_{i}$ is given by $u_{i}=\sum_{j=1}^{J} t_{i, j} h_{i, j}$. Here $t_{i, j}$ and $h_{i, j}$ are, respectively, the share of total time spent and level of happiness for activity $j$ in group $j$. Let $s_{i}$ denote the share in the sample of those in group $i$. The expressions $\bar{t}_{j}=s_{1} t_{1, j}+s_{2} t_{2, j}$ and $\bar{h}_{j}=s_{1} h_{1, j}+s_{2} h_{2, j}$ then respectively denotes the average level of time and happiness for activity $j$. Let $\Delta u_{1,2} \equiv u_{1}-u_{2}$ be the time-weighted happiness gap between groups 1 and 2 (e.g., men and women).

We wish to show that the following identity holds: $\Delta u_{1,2}=\sum_{j=1}^{J} \bar{t}_{j} h_{1, j}-\sum_{j=1}^{J} \bar{t}_{j} h_{2, j}+\sum_{j=1}^{J} t_{1, j} \bar{h}_{j}-$ $\sum_{j=1}^{J} t_{2, j} \bar{h}_{j}$. To do so, expand each of the terms in $\Delta u_{1,2}$ :

$$
\begin{gathered}
\Delta u_{1,2}=\sum_{j=1}^{J} \bar{t}_{j} h_{1, j}-\bar{t}_{j} h_{2, j}+t_{1, j} \bar{h}_{j}-t_{2, j} \bar{h}_{j} \\
=\sum_{j=1}^{J}\left(s_{1} t_{1, j}+s_{2} t_{2, j}\right) h_{1, j}-\left(s_{1} t_{1, j}+s_{2} t_{2, j}\right) h_{2, j}+t_{1, j}\left(s_{1} h_{1, j}+s_{2} h_{2, j}\right)-t_{2, j}\left(s_{1} h_{1, j}+s_{2} h_{2, j}\right) \\
=\sum_{j=1}^{J} s_{1} t_{1, j} h_{1, j}+s_{2} t_{2, j} h_{1, j}-s_{1} t_{1, j} h_{2, j}-s_{2} t_{2, j} h_{2, j}+t_{1, j} s_{1} h_{1, j}+t_{1, j} s_{2} h_{2, j}-t_{2, j} s_{1} h_{1, j}-t_{2, j} s_{2} h_{2, j} \\
=\sum_{j=1}^{J} 2 s_{1} t_{1, j} h_{1, j}+\left(s_{2}-s_{1}\right) t_{2, j} h_{1, j}+\left(s_{2}-s_{1}\right) t_{1, j} h_{2, j}-2 s_{2} t_{2, j} h_{2, j}
\end{gathered}
$$

Now assume that $s_{1}=s_{2}=s$. In practice, this can be ensured with sampling weights. Since $2 s=1$, the last line of the above expression can then be written as $\Delta u_{1,2}=\sum_{j=1}^{J} t_{1, j} h_{1, j}-t_{2, j} h_{2, j}=u_{1}-u_{2}$, as is desired. The result is straightforwardly generalised to an arbitrary number of groups. 


\section{Appendix B. Reversing the Results in Table 2 by Means of Positive Monotonic Transformations}

For further details and derivations on the method outlined below, see Kaiser \& Vendrik (2020).

Let a person's reported level of life satisfaction $l s_{i}$ (or activity-level happiness $h_{i j}$ ) be recorded by a set of strictly increasing numerical labels $r_{1}<r_{2}<\cdots<r_{k}<\cdots<r_{K}$. Here, $r_{1}$ denotes the first (i.e., lowest) response category, $r_{2}$ denotes the second response category, $r_{k}$ denotes the $\mathrm{k}^{\text {th }}$ response category. Standardly responses are recorded in equal intervals, e.g., $r_{1}=1, r_{2}=2, \ldots, r_{k}=k$. However, if responses only carry ordinal information, any positive monotonic transformation of these labels is equally permissible.

We can write $l s_{i} \in\left\{r_{1}, r_{2}, \ldots, r_{k}, \ldots, r_{K}\right\}$ in terms of dummies $d_{i}^{(k)}=\mathbb{1}\left\{l s_{i}>k\right\}$. In particular, since all terms cancel, we have it that $l s_{i}=\sum_{k}\left(r_{k+1}-r_{k}\right) d_{i}^{(k)}$. Denote the estimated OLS coefficient from a regression of $l s$ on a covariate $x$ (+possibly controls) by $\beta$, and the OLS coefficient from a regression of $d_{i}^{(k)}$ on the same covariate as $\beta_{d}^{(k)}$. Given the relation for $l s_{i}$, it is straightforward to show that $\beta=$ $\sum_{k}\left(r_{k+1}-r_{k}\right) \beta_{d}^{(k)}$. Since the numerical labels $r_{k}$ are strictly increasing, the terms $r_{k+1}-r_{k}$ are positive for any positive monotonic transformation of $l s_{i}$. Hence, the sum $\sum_{k}\left(r_{k+1}-r_{k}\right) \beta_{d}^{(k)}$ can only change sign for some assignment of labels for $r_{k}$ when not all coefficients $\beta_{d}^{(k)}$ have the same sign.

This argument implies the following condition:

Reversal condition: There exists some positive monotonic transformation of $l s$ under which the OLS coefficient $\beta$ changes sign if and only if $\beta_{d}^{(k)}$ changes sign for at least one $k$.

As in appendix A, time-weighted happiness $u_{i}$, is given by $u_{i}=\sum_{j} t_{i j} h_{i j}$, where $h_{i, j}$ denotes activity-level happiness. Similar to life satisfaction, we can write $u_{i}$ in terms of activity-level dummies $d_{i j}^{(k)}=\mathbb{1}\left\{h_{i j}>k\right\}$, i.e., as $u_{i}=\sum_{k}\left(r_{k+1}-r_{k}\right) \sum_{j} t_{i j} d_{i j}^{(k)}$. Now denoting the estimated OLS coefficient from a regression of $u$ on a covariate $x$ (+possibly controls) by $\beta$, and the OLS coefficient from a regression of $\sum_{j} t_{i j} d_{i j}^{(k)}$ on the same covariate as $\beta_{d}^{(k)}$, it is again easily shown that $\beta=\sum_{k}\left(r_{k+1}-r_{k}\right) \beta_{d}^{(k)}$. Thus, the reversal condition also holds for time-weighted happiness.

In the main text, we saw that for life satisfaction among men, the coefficients in Table 2 on income, having children, and unemployment were statistically significant, and shown to be reversible in Table A3. In addition, among women, the coefficient on having a college education, and the coefficient on being employed were also statistically significant and reversible. Concerning time-weighted happiness, only the coefficient on having a college education was reversible and statistically significant (for both genders).

For these variables, we numerically searched for positive monotonic transformations that would reverse the coefficients displayed in Table 2. In particular we searched over respectively convex and concave transformations of the form $\widetilde{l s}_{i}=\exp \left(c * l s_{i}\right)$ and $\widetilde{l s_{i}}=-\exp \left(-c * l s_{i}\right)$, where we vary the value of $c$ (c.f. Bond \& Lang, 2019).

The larger $c$, the more convex/concave the transformation, and the more non-linear respondents' scale use. For example, in the convex (concave) case, $c=1$ implies that the differences between response categories grows (declines) by a factor of $\exp (c=1) \approx 2.718$. In the case of a scale with 11 response categories, this would imply that the difference between the $11^{\text {th }}$ and $10^{\text {th }}$ response category is more than 8,000 times larger than the difference between the $1^{\text {st }}$ and $2^{\text {nd }}$ response category. ${ }^{15}$ This is clearly implausible. More

${ }^{15}$ Since $\exp (11)-\exp (10)=37847, \exp (2)-\exp (1)=4.671$, and $37847 / 4.671=8103$. 
generally, using previous evidence from psychology and economics, Kaiser \& Vendrik (2020) suggest that required values of $c$ larger than 0.4 are implausible.

As listed in Appendix Table 4, we find that required values of c are larger than 0.4 for most variables. Hence, for most variables, reversals of their effects are implausible. However, the required values of $c$ to reverse the effect of being employed on women's life satisfaction $(c=0.36)$ and to reverse the effect of a college education on time-weighted happiness among women $(c=0.28)$, are sufficiently small to be plausible. Thus, for these variables, we should not be confident in the sign of the coefficients shown in Table 2. 


\section{Appendix C. Additional Tables}

Appendix Table 1. Mean Characteristics, 1985 AUTP and 2010-13 ATUS

\begin{tabular}{|c|c|c|c|c|c|c|c|c|}
\hline \multirow[t]{2}{*}{ Survey } & \multicolumn{4}{|c|}{1985 AUTP } & \multicolumn{4}{|c|}{ 2010, 2012-13 ATUS } \\
\hline & Mean & SD & Min & $\operatorname{Max}$ & Mean & SD & Min & $\operatorname{Max}$ \\
\hline Happiness & 7.13 & 1.24 & 0 & 10 & 4.37 & 1.32 & 0 & 6 \\
\hline Life Satisfaction & & & & & 7.12 & 2.02 & 0 & 10 \\
\hline Male & 0.47 & 0.50 & 0 & 1 & 0.48 & 0.50 & 0 & 1 \\
\hline Age & 42.78 & 17.95 & 18 & 85 & 46.83 & 17.66 & 18 & 85 \\
\hline Married & 0.64 & 0.48 & 0 & 1 & 0.56 & 0.50 & 0 & 1 \\
\hline Number of adults & 2.25 & 0.96 & 1 & 6 & 2.24 & 0.98 & 1 & 8 \\
\hline Number of children & 0.64 & 1.00 & 0 & 6 & 0.69 & 1.10 & 0 & 10 \\
\hline H.S. Degree or Less & 0.66 & 0.47 & 0 & 1 & 0.43 & 0.49 & 0 & 1 \\
\hline Some College or More & 0.34 & 0.47 & 0 & 1 & 0.57 & 0.49 & 0 & 1 \\
\hline 1st Income Quartile & 0.17 & 0.38 & 0 & 1 & 0.22 & 0.41 & 0 & 1 \\
\hline 2nd Income Quartile & 0.24 & 0.43 & 0 & 1 & 0.26 & 0.44 & 0 & 1 \\
\hline 3rd Income Quartile & 0.22 & 0.41 & 0 & 1 & 0.31 & 0.46 & 0 & 1 \\
\hline 4th Income Quartile & 0.24 & 0.43 & 0 & 1 & 0.20 & 0.40 & 0 & 1 \\
\hline Employed & 0.67 & 0.47 & 0 & 1 & 0.63 & 0.48 & 0 & 1 \\
\hline Unemployed & 0.03 & 0.18 & 0 & 1 & 0.06 & 0.24 & 0 & 1 \\
\hline Retired & 0.15 & 0.36 & 0 & 1 & 0.16 & 0.36 & 0 & 1 \\
\hline $\begin{array}{l}\text { Unweighted Number } \\
\text { of Individuals }\end{array}$ & \multicolumn{4}{|c|}{2632} & \multicolumn{4}{|c|}{33575} \\
\hline
\end{tabular}

Note: This table reports the wellbeing measures and demographic characteristics of our analysis sample in 1985 and 2010-13. Results are weighted using survey weights. 
Appendix Table 2. Classification of activities

\begin{tabular}{ll}
\hline Market work & $\begin{array}{l}\text { main paid work, second job, work breaks, other time at workplace, time looking for work, } \\
\text { travel related to work }\end{array}$ \\
\hline Domestic work & $\begin{array}{l}\text { food preparation, cooking, set table, cleaning, laundry, home repairs, maintain vehicle, } \\
\text { other domestic work }\end{array}$ \\
\hline Shopping & purchase routine goods, consumer durables, personal services, or other services \\
\hline In-home free time & $\begin{array}{l}\text { receive or visit friends, playing games, crafts, hobbies, relaxing, reading, conversation, } \\
\text { phone, texting, using computer for leisure }\end{array}$ \\
\hline Out-of-home free-time & $\begin{array}{l}\text { attending sporting event, attending movies, attending parties, eating and drinking (at } \\
\text { restaurant), sports, exercise, walking, biking, fishing, gardening, pet care }\end{array}$ \\
\hline Watching TV & watching TV and movies \\
\hline Social care & $\begin{array}{l}\text { general/medical care of children, playing/reading/talking with children, supervise/help } \\
\text { with homework, care for adults }\end{array}$ \\
\hline Travel & $\begin{array}{l}\text { travel related to leisure, personal care, education, consumption, care for others, } \\
\text { volunteering/worship, or other purpose }\end{array}$ \\
\hline Education & schooling, homework, other education or training \\
\hline Civic/religious activity & voluntary acts, political and civic acts, worship and religious acts \\
\hline Personal care & personal activities, wash, dress, personal care, personal medical care \\
\hline Sleeping & sleep, naps and rest \\
\hline Eating & meals at work, other meals/snacks \\
\hline
\end{tabular}

Note: This table reports the list of activities that are included in 13 broad activity categories used in our analysis. 
Appendix Table 3a. Relationships between Dichotomized Life Satisfaction and Socio-economic Characteristics, Men, ATUS 2012-13

\begin{tabular}{|c|c|c|c|c|c|c|c|c|c|c|}
\hline Dependent Variable & $\begin{array}{c}\text { Life } \\
\text { Satisfaction } \\
(0,1-10)\end{array}$ & $\begin{array}{c}\text { Life } \\
\text { Satisfaction } \\
(0-1,2-10)\end{array}$ & $\begin{array}{c}\text { Life } \\
\text { Satisfaction } \\
(0-2,3-10)\end{array}$ & $\begin{array}{c}\text { Life } \\
\text { Satisfaction } \\
(0-3,4-10)\end{array}$ & $\begin{array}{c}\text { Life } \\
\text { Satisfaction } \\
(0-4,5-10)\end{array}$ & $\begin{array}{c}\text { Life } \\
\text { Satisfaction } \\
(0-5,5-10)\end{array}$ & $\begin{array}{c}\text { Life } \\
\text { Satisfaction } \\
(0-6,7-10)\end{array}$ & $\begin{array}{c}\text { Life } \\
\text { Satisfaction } \\
(0-7,8-10)\end{array}$ & $\begin{array}{c}\text { Life } \\
\text { Satisfaction } \\
(0-8,9-10)\end{array}$ & $\begin{array}{c}\text { Life } \\
\text { Satisfaction } \\
(0-9,10)\end{array}$ \\
\hline Married & $\begin{array}{c}0.004 \\
(0.003)\end{array}$ & $\begin{array}{l}0.007 * \\
(0.004)\end{array}$ & $\begin{array}{c}0.018 * * * \\
(0.005)\end{array}$ & $\begin{array}{c}0.038 * * * \\
(0.007)\end{array}$ & $\begin{array}{c}0.048 * * * \\
(0.010)\end{array}$ & $\begin{array}{c}0.087 * * * \\
(0.015)\end{array}$ & $\begin{array}{c}0.107 * * * \\
(0.016)\end{array}$ & $\begin{array}{c}0.099 * * * \\
(0.016)\end{array}$ & $\begin{array}{c}0.058 * * * \\
(0.013)\end{array}$ & $\begin{array}{c}0.016 \\
(0.011)\end{array}$ \\
\hline Age & $\begin{array}{c}-0.001 * * \\
(0.000)\end{array}$ & $\begin{array}{c}-0.002 * * * \\
(0.001)\end{array}$ & $\begin{array}{c}-0.003 * * * \\
(0.001)\end{array}$ & $\begin{array}{c}-0.006 * * * \\
(0.001)\end{array}$ & $\begin{array}{c}-0.005 * * * \\
(0.002)\end{array}$ & $\begin{array}{c}-0.010 * * * \\
(0.002)\end{array}$ & $\begin{array}{c}-0.012 * * * \\
(0.003)\end{array}$ & $\begin{array}{c}-0.011 * * * \\
(0.003)\end{array}$ & $\begin{array}{c}-0.008 * * * \\
(0.002)\end{array}$ & $\begin{array}{c}-0.006 * * * \\
(0.002)\end{array}$ \\
\hline $\mathrm{Age}^{2}$ & $\begin{array}{c}0.000 * * \\
(0.000)\end{array}$ & $\begin{array}{c}0.000 * * * \\
(0.000)\end{array}$ & $\begin{array}{c}0.000 * * * \\
(0.000)\end{array}$ & $\begin{array}{c}0.000 * * * \\
(0.000)\end{array}$ & $\begin{array}{c}0.000 * * * \\
(0.000)\end{array}$ & $\begin{array}{c}0.000 * * * \\
(0.000)\end{array}$ & $\begin{array}{c}0.000 * * * \\
(0.000)\end{array}$ & $\begin{array}{c}0.000 * * * \\
(0.000)\end{array}$ & $\begin{array}{c}0.000 * * * \\
(0.000)\end{array}$ & $\begin{array}{c}0.000 * * * \\
(0.000)\end{array}$ \\
\hline Have Children & $\begin{array}{l}-0.000 \\
(0.003)\end{array}$ & $\begin{array}{c}0.005 \\
(0.004)\end{array}$ & $\begin{array}{c}0.007 \\
(0.005)\end{array}$ & $\begin{array}{c}0.009 \\
(0.007)\end{array}$ & $\begin{array}{c}0.008 \\
(0.011)\end{array}$ & $\begin{array}{c}0.006 \\
(0.015)\end{array}$ & $\begin{array}{c}0.017 \\
(0.017)\end{array}$ & $\begin{array}{c}0.041 * * \\
(0.017)\end{array}$ & $\begin{array}{c}0.035 * * \\
(0.014)\end{array}$ & $\begin{array}{c}0.032 * * * \\
(0.011)\end{array}$ \\
\hline Some College or More & $\begin{array}{c}0.004 \\
(0.003)\end{array}$ & $\begin{array}{c}0.002 \\
(0.003)\end{array}$ & $\begin{array}{c}0.001 \\
(0.005)\end{array}$ & $\begin{array}{c}0.006 \\
(0.007)\end{array}$ & $\begin{array}{c}0.005 \\
(0.010)\end{array}$ & $\begin{array}{c}0.048 * * * \\
(0.013)\end{array}$ & $\begin{array}{c}0.031 * * \\
(0.015)\end{array}$ & $\begin{array}{l}-0.006 \\
(0.016)\end{array}$ & $\begin{array}{c}-0.039 * * * \\
(0.012)\end{array}$ & $\begin{array}{c}-0.050 * * * \\
(0.010)\end{array}$ \\
\hline 2nd Income Quartile & $\begin{array}{c}0.004 \\
(0.005)\end{array}$ & $\begin{array}{c}0.005 \\
(0.006)\end{array}$ & $\begin{array}{l}0.015^{*} \\
(0.008)\end{array}$ & $\begin{array}{c}0.031 * * * \\
(0.011)\end{array}$ & $\begin{array}{c}0.036 * * \\
(0.014)\end{array}$ & $\begin{array}{c}0.044 * * \\
(0.020)\end{array}$ & $\begin{array}{c}0.042 * * \\
(0.021)\end{array}$ & $\begin{array}{l}-0.015 \\
(0.021)\end{array}$ & $\begin{array}{c}-0.030 * \\
(0.018)\end{array}$ & $\begin{array}{c}-0.028^{*} \\
(0.015)\end{array}$ \\
\hline 3rd Income Quartile & $\begin{array}{l}0.008 * \\
(0.004)\end{array}$ & $\begin{array}{c}0.012 * * \\
(0.005)\end{array}$ & $\begin{array}{c}0.024 * * * \\
(0.007)\end{array}$ & $\begin{array}{c}0.038 * * * \\
(0.011)\end{array}$ & $\begin{array}{c}0.039 * * * \\
(0.015)\end{array}$ & $\begin{array}{c}0.076 * * * \\
(0.020)\end{array}$ & $\begin{array}{c}0.063 * * * \\
(0.021)\end{array}$ & $\begin{array}{c}0.004 \\
(0.021)\end{array}$ & $\begin{array}{c}-0.044 * * * \\
(0.017)\end{array}$ & $\begin{array}{c}-0.041 * * * \\
(0.014)\end{array}$ \\
\hline 4th Income Quartile & $\begin{array}{c}0.012 * * * \\
(0.004)\end{array}$ & $\begin{array}{c}0.014 * * \\
(0.006)\end{array}$ & $\begin{array}{c}0.030 * * * \\
(0.009)\end{array}$ & $\begin{array}{c}0.051 * * * \\
(0.011)\end{array}$ & $\begin{array}{c}0.074 * * * \\
(0.016)\end{array}$ & $\begin{array}{c}0.149 * * * \\
(0.021)\end{array}$ & $\begin{array}{c}0.182 * * * \\
(0.025)\end{array}$ & $\begin{array}{c}0.096 * * * \\
(0.026)\end{array}$ & $\begin{array}{c}0.006 \\
(0.021)\end{array}$ & $\begin{array}{c}-0.034 * * \\
(0.016)\end{array}$ \\
\hline Employed & $\begin{array}{c}0.015 * * * \\
(0.006)\end{array}$ & $\begin{array}{c}0.024 * * * \\
(0.008)\end{array}$ & $\begin{array}{c}0.035 * * * \\
(0.010)\end{array}$ & $\begin{array}{c}0.053 * * * \\
(0.013)\end{array}$ & $\begin{array}{c}0.084 * * * \\
(0.019)\end{array}$ & $\begin{array}{c}0.121 * * * \\
(0.023)\end{array}$ & $\begin{array}{c}0.090 * * * \\
(0.025)\end{array}$ & $\begin{array}{c}0.080 * * * \\
(0.024)\end{array}$ & $\begin{array}{c}0.020 \\
(0.020)\end{array}$ & $\begin{array}{c}0.014 \\
(0.016)\end{array}$ \\
\hline Unemployed & $\begin{array}{c}0.017 * * * \\
(0.006)\end{array}$ & $\begin{array}{c}0.024 * * * \\
(0.009)\end{array}$ & $\begin{array}{c}0.004 \\
(0.016)\end{array}$ & $\begin{array}{l}-0.018 \\
(0.023)\end{array}$ & $\begin{array}{l}-0.044 \\
(0.032)\end{array}$ & $\begin{array}{c}-0.074 * * \\
(0.038)\end{array}$ & $\begin{array}{c}-0.102 * * * \\
(0.038)\end{array}$ & $\begin{array}{c}-0.068^{*} \\
(0.037)\end{array}$ & $\begin{array}{l}-0.031 \\
(0.032)\end{array}$ & $\begin{array}{l}-0.028 \\
(0.022)\end{array}$ \\
\hline Retired & $\begin{array}{l}0.011^{*} \\
(0.006)\end{array}$ & $\begin{array}{c}0.018 * * \\
(0.008)\end{array}$ & $\begin{array}{c}0.031 * * * \\
(0.010)\end{array}$ & $\begin{array}{c}0.042 * * * \\
(0.014)\end{array}$ & $\begin{array}{c}0.069 * * * \\
(0.019)\end{array}$ & $\begin{array}{c}0.097 * * * \\
(0.027)\end{array}$ & $\begin{array}{c}0.067 * * \\
(0.030)\end{array}$ & $\begin{array}{c}0.092 * * * \\
(0.031)\end{array}$ & $\begin{array}{c}0.025 \\
(0.027)\end{array}$ & $\begin{array}{c}0.020 \\
(0.022)\end{array}$ \\
\hline Interview times & Yes & Yes & Yes & Yes & Yes & Yes & Yes & Yes & Yes & Yes \\
\hline $\begin{array}{l}\text { R-squared } \\
\text { Number of Observations }\end{array}$ & 0.012 & 0.017 & 0.025 & 0.036 & \multicolumn{5}{|c|}{8,732} & 0.027 \\
\hline
\end{tabular}

Note: Life satisfaction measures are normalized with mean zero and standard deviation of one. Interview times include interview month, year, and day of week. Estimates are weighted using survey weights. Coefficients that change signs are marked in blue. 
Appendix Table 3b. Relationships between Dichotomized Life Satisfaction and Socio-economic Characteristics, Women, ATUS 2012-13

\begin{tabular}{|c|c|c|c|c|c|c|c|c|c|c|}
\hline Dependent Variable & $\begin{array}{c}\text { Life } \\
\text { Satisfaction } \\
(0,1-10)\end{array}$ & $\begin{array}{c}\text { Life } \\
\text { Satisfaction } \\
(0-1,2-10)\end{array}$ & $\begin{array}{c}\text { Life } \\
\text { Satisfaction } \\
(0-2,3-10)\end{array}$ & $\begin{array}{c}\text { Life } \\
\text { Satisfaction } \\
(0-3,4-10)\end{array}$ & $\begin{array}{c}\text { Life } \\
\text { Satisfaction } \\
(0-4,5-10)\end{array}$ & $\begin{array}{c}\text { Life } \\
\text { Satisfaction } \\
(0-5,5-10)\end{array}$ & $\begin{array}{c}\text { Life } \\
\text { Satisfaction } \\
(0-6,7-10)\end{array}$ & $\begin{array}{c}\text { Life } \\
\text { Satisfaction } \\
(0-7,8-10)\end{array}$ & $\begin{array}{c}\text { Life } \\
\text { Satisfaction } \\
(0-8,9-10)\end{array}$ & $\begin{array}{c}\text { Life } \\
\text { Satisfaction } \\
(0-9,10)\end{array}$ \\
\hline Married & $\begin{array}{c}0.007 * * * \\
(0.002)\end{array}$ & $\begin{array}{c}0.011 * * * \\
(0.003)\end{array}$ & $\begin{array}{c}0.019 * * * \\
(0.004)\end{array}$ & $\begin{array}{c}0.038 * * * \\
(0.006)\end{array}$ & $\begin{array}{c}0.052 * * * \\
(0.008)\end{array}$ & $\begin{array}{c}0.096 * * * \\
(0.012)\end{array}$ & $\begin{array}{c}0.122 * * * \\
(0.013)\end{array}$ & $\begin{array}{c}0.123 * * * \\
(0.014)\end{array}$ & $\begin{array}{c}0.099 * * * \\
(0.012)\end{array}$ & $\begin{array}{c}0.050 * * * \\
(0.010)\end{array}$ \\
\hline Age & $\begin{array}{c}-0.001 * \\
(0.000)\end{array}$ & $\begin{array}{c}-0.001 * * * \\
(0.000)\end{array}$ & $\begin{array}{c}-0.002 * * * \\
(0.001)\end{array}$ & $\begin{array}{c}-0.005^{* * *} \\
(0.001)\end{array}$ & $\begin{array}{c}-0.006^{* * *} \\
(0.001)\end{array}$ & $\begin{array}{c}-0.009 * * * \\
(0.002)\end{array}$ & $\begin{array}{c}-0.005^{* *} \\
(0.002)\end{array}$ & $\begin{array}{c}-0.004 * \\
(0.002)\end{array}$ & $\begin{array}{l}-0.003 \\
(0.002)\end{array}$ & $\begin{array}{l}-0.002 \\
(0.002)\end{array}$ \\
\hline $\mathrm{Age}^{2}$ & $\begin{array}{c}0.000 \\
(0.000)\end{array}$ & $\begin{array}{c}0.000 * * \\
(0.000)\end{array}$ & $\begin{array}{c}0.000 * * \\
(0.000)\end{array}$ & $\begin{array}{c}0.000 * * * \\
(0.000)\end{array}$ & $\begin{array}{c}0.000 * * * \\
(0.000)\end{array}$ & $\begin{array}{c}0.000 * * * \\
(0.000)\end{array}$ & $\begin{array}{c}0.000 * * \\
(0.000)\end{array}$ & $\begin{array}{c}0.000 * * * \\
(0.000)\end{array}$ & $\begin{array}{c}0.000 * * \\
(0.000)\end{array}$ & $\begin{array}{c}0.000 * * \\
(0.000)\end{array}$ \\
\hline Have Children & $\begin{array}{c}0.001 \\
(0.002)\end{array}$ & $\begin{array}{c}0.000 \\
(0.003)\end{array}$ & $\begin{array}{l}-0.004 \\
(0.004)\end{array}$ & $\begin{array}{l}-0.002 \\
(0.006)\end{array}$ & $\begin{array}{l}-0.005 \\
(0.008)\end{array}$ & $\begin{array}{c}0.015 \\
(0.013)\end{array}$ & $\begin{array}{c}0.031 * * \\
(0.015)\end{array}$ & $\begin{array}{l}0.030^{*} \\
(0.016)\end{array}$ & $\begin{array}{l}-0.001 \\
(0.013)\end{array}$ & $\begin{array}{c}0.009 \\
(0.011)\end{array}$ \\
\hline Some College or More & $\begin{array}{c}0.002 \\
(0.002)\end{array}$ & $\begin{array}{c}0.004 \\
(0.003) \\
\end{array}$ & $\begin{array}{c}0.006 \\
(0.005) \\
\end{array}$ & $\begin{array}{c}0.005 \\
(0.006)\end{array}$ & $\begin{array}{l}-0.007 \\
(0.008) \\
\end{array}$ & $\begin{array}{c}0.014 \\
(0.012)\end{array}$ & $\begin{array}{l}0.007 \\
(0.013) \\
\end{array}$ & $\begin{array}{c}-0.044 * * * \\
(0.014)\end{array}$ & $\begin{array}{c}-0.077 * * * \\
(0.013)\end{array}$ & $\begin{array}{c}-0.077 * * * \\
(0.011)\end{array}$ \\
\hline 2nd Income Quartile & $\begin{array}{c}0.008 * * \\
(0.004)\end{array}$ & $\begin{array}{c}0.010 * * \\
(0.005)\end{array}$ & $\begin{array}{c}0.021 * * * \\
(0.006)\end{array}$ & $\begin{array}{c}0.020 * * \\
(0.008)\end{array}$ & $\begin{array}{c}0.031 * * * \\
(0.010)\end{array}$ & $\begin{array}{c}0.049 * * * \\
(0.016)\end{array}$ & $\begin{array}{c}0.048^{* * * *} \\
(0.017)\end{array}$ & $\begin{array}{c}0.049 * * * \\
(0.018)\end{array}$ & $\begin{array}{c}0.018 \\
(0.015)\end{array}$ & $\begin{array}{c}0.004 \\
(0.013)\end{array}$ \\
\hline 3rd Income Quartile & $\begin{array}{c}0.012 * * * \\
(0.003)\end{array}$ & $\begin{array}{c}0.013 * * * \\
(0.004)\end{array}$ & $\begin{array}{c}0.023 * * * \\
(0.006)\end{array}$ & $\begin{array}{c}0.027 * * * \\
(0.009)\end{array}$ & $\begin{array}{c}0.037 * * * \\
(0.012)\end{array}$ & $\begin{array}{c}0.094 * * * \\
(0.016)\end{array}$ & $\begin{array}{c}0.090 * * * \\
(0.018)\end{array}$ & $\begin{array}{c}0.078 * * * \\
(0.019)\end{array}$ & $\begin{array}{c}0.011 \\
(0.016)\end{array}$ & $\begin{array}{l}-0.013 \\
(0.014)\end{array}$ \\
\hline 4th Income Quartile & $\begin{array}{c}0.012 * * * \\
(0.003)\end{array}$ & $\begin{array}{c}0.014 * * \\
(0.006)\end{array}$ & $\begin{array}{c}0.028 * * * \\
(0.007)\end{array}$ & $\begin{array}{c}0.038 * * * \\
(0.009)\end{array}$ & $\begin{array}{c}0.066 * * * \\
(0.012)\end{array}$ & $\begin{array}{c}0.143 * * * \\
(0.017)\end{array}$ & $\begin{array}{c}0.149 * * * \\
(0.021)\end{array}$ & $\begin{array}{c}0.142 * * * \\
(0.023)\end{array}$ & $\begin{array}{c}0.050 * * * \\
(0.019)\end{array}$ & $\begin{array}{c}0.001 \\
(0.016)\end{array}$ \\
\hline Employed & $\begin{array}{c}0.009 * * * \\
(0.003)\end{array}$ & $\begin{array}{c}0.015 * * * \\
(0.004)\end{array}$ & $\begin{array}{c}0.023 * * * \\
(0.006)\end{array}$ & $\begin{array}{c}0.039 * * * \\
(0.008)\end{array}$ & $\begin{array}{c}0.054 * * * \\
(0.010)\end{array}$ & $\begin{array}{c}0.076 * * * \\
(0.015)\end{array}$ & $\begin{array}{c}0.052 * * * \\
(0.017)\end{array}$ & $\begin{array}{l}-0.008 \\
(0.018)\end{array}$ & $\begin{array}{l}-0.027 * \\
(0.015)\end{array}$ & $\begin{array}{c}-0.037 * * * \\
(0.013)\end{array}$ \\
\hline Unemployed & $\begin{array}{c}0.002 \\
(0.007)\end{array}$ & $\begin{array}{l}-0.003 \\
(0.011)\end{array}$ & $\begin{array}{l}-0.003 \\
(0.014)\end{array}$ & $\begin{array}{l}-0.016 \\
(0.018)\end{array}$ & $\begin{array}{l}-0.034 \\
(0.024)\end{array}$ & $\begin{array}{c}-0.100 * * * \\
(0.031)\end{array}$ & $\begin{array}{c}-0.095 * * * \\
(0.032)\end{array}$ & $\begin{array}{c}-0.080 * * \\
(0.031)\end{array}$ & $\begin{array}{l}-0.033 \\
(0.027)\end{array}$ & $\begin{array}{l}-0.013 \\
(0.024)\end{array}$ \\
\hline Retired & $\begin{array}{c}0.009 * * \\
(0.004)\end{array}$ & $\begin{array}{c}0.017 * * * \\
(0.005)\end{array}$ & $\begin{array}{c}0.031 * * * \\
(0.008)\end{array}$ & $\begin{array}{c}0.042 * * * \\
(0.010)\end{array}$ & $\begin{array}{c}0.071 * * * \\
(0.013)\end{array}$ & $\begin{array}{c}0.102 * * * \\
(0.021)\end{array}$ & $\begin{array}{c}0.100 * * * \\
(0.023)\end{array}$ & $\begin{array}{c}0.079 * * * \\
(0.024)\end{array}$ & $\begin{array}{l}0.044 * \\
(0.024)\end{array}$ & $\begin{array}{c}0.025 \\
(0.022)\end{array}$ \\
\hline Interview times & Yes & Yes & Yes & Yes & Yes & Yes & Yes & Yes & Yes & Yes \\
\hline R-squared & 0.013 & 0.016 & 0.025 & 0.032 & 0.036 & 0.058 & 0.053 & 0.052 & 0.046 & 0.047 \\
\hline Number of Observations & \multicolumn{10}{|c|}{11,038} \\
\hline
\end{tabular}

Note: Life satisfaction measures are normalized with mean zero and standard deviation of one. Interview times include interview month, year, and day of week. Estimates are weighted using survey weights. Coefficients that change signs are marked in blue. 
Appendix Table 3c. Relationships between Dichotomized Happiness and Socio-economic Characteristics, ATUS 2012-13

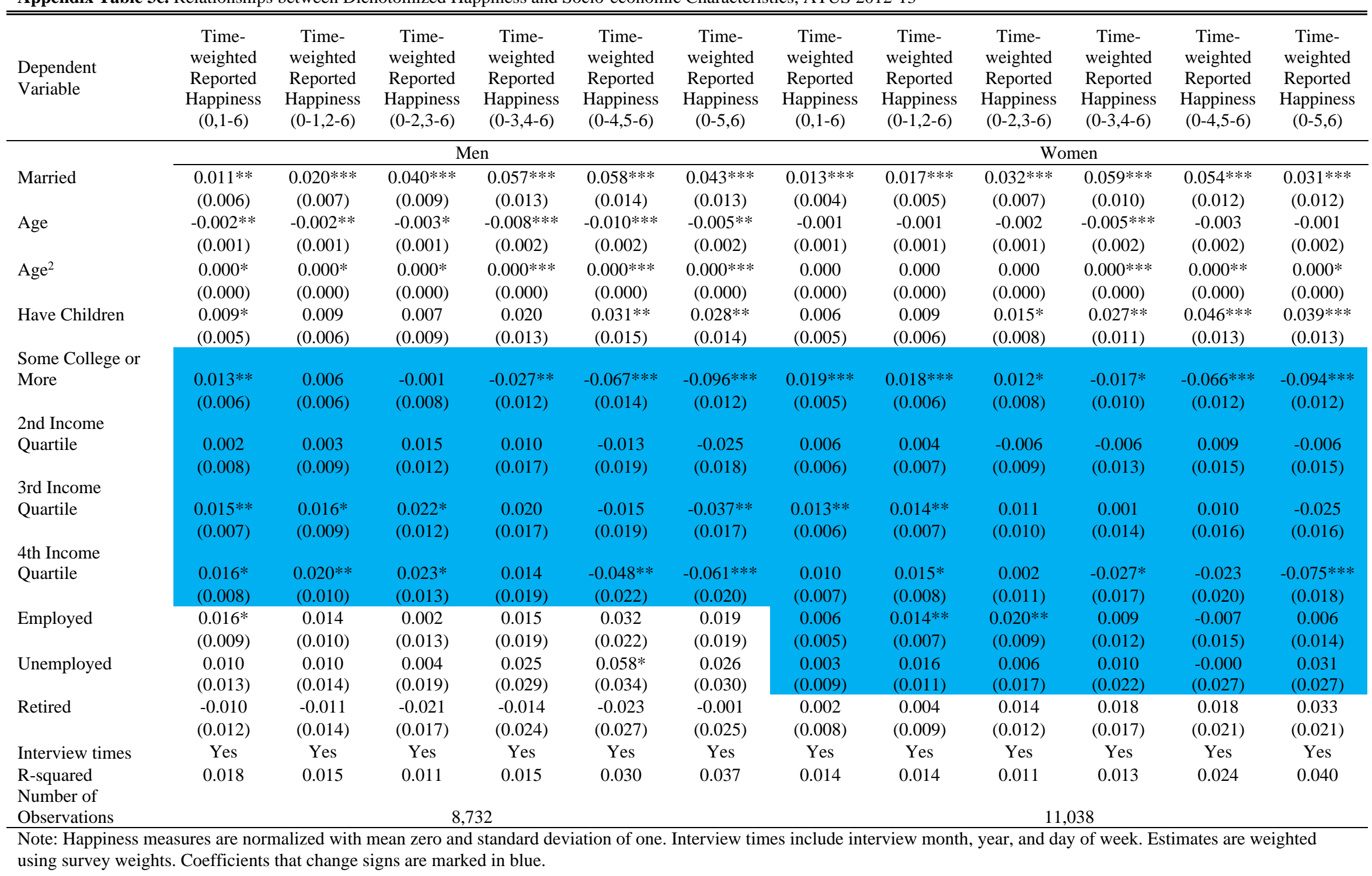


Appendix Table 4. Values of $c$ required to reverse coefficient estimates

\section{Estimate}

Income on life satisfaction (men)

Children on life satisfaction (men)

Unemployment on life satisfaction (men)

Income on life satisfaction (women)

College on life satisfaction (women)

Employment on life satisfaction (women)

Unemployment on life satisfaction (women)

College on time-weighted happiness (men)

College on time-weighted happiness (women)

Note: Required values of $c$ are found numerically.
Required value for $\mathrm{c}$

0.93 (convex)

3.05 (concave)

0.44 (convex)

1.29 (convex)

0.36 (concave)

0.33 (convex)

1.16 (concave)

0.77 (concave)

0.28 (concave) 
TIME USE AND HAPPINESS: EVIDENCE ACROSS THREE DECADES

\begin{tabular}{|c|c|c|c|c|c|}
\hline \multirow{2}{*}{$\begin{array}{l}\text { Dependent Variable } \\
\text { Z(Happiness based on Individual FE) }\end{array}$} & \multicolumn{5}{|c|}{ Life Satisfaction } \\
\hline & $\begin{array}{c}0.500 * * * \\
(0.043)\end{array}$ & & $\begin{array}{c}0.496 * * * \\
(0.041)\end{array}$ & & $\begin{array}{c}0.486 * * * \\
(0.083)\end{array}$ \\
\hline $\mathrm{Z}$ (Happiness based on time-use) & & $\begin{array}{c}0.439 * * * \\
(0.041)\end{array}$ & & $\begin{array}{c}0.469 * * * \\
(0.041)\end{array}$ & $\begin{array}{c}0.012 \\
(0.081)\end{array}$ \\
\hline Control for Demogr. Characteristics, Diary Times & No & No & Yes & Yes & Yes \\
\hline R-squared & 0.069 & 0.053 & 0.156 & 0.147 & 0.156 \\
\hline Mean of Dep. Var. & & & 1.895 & & \\
\hline Number of Observations & & & 4,495 & & \\
\hline
\end{tabular}

Note: This table replicates Table 1 using the UK time-use surveys in 2014-15. 
TIME USE AND HAPPINESS: EVIDENCE ACROSS THREE DECADES

Appendix Table 6. Relationships between Life Satisfaction or Happiness and Socio-economic Characteristics, UKTUS 2014-15

\begin{tabular}{|c|c|c|c|c|}
\hline \multirow[b]{2}{*}{ Wellbeing measure } & \multicolumn{2}{|c|}{ Men } & \multicolumn{2}{|c|}{ Women } \\
\hline & $\begin{array}{c}\text { Time- weighted } \\
\text { Reported Happiness }\end{array}$ & Life Satisfaction & $\begin{array}{c}\text { Time- weighted } \\
\text { Reported Happiness }\end{array}$ & Life Satisfaction \\
\hline Married & $\begin{array}{l}0.129 * * \\
(0.060)\end{array}$ & $\begin{array}{c}0.405 * * * \\
(0.079)\end{array}$ & $\begin{array}{c}0.077 \\
(0.047)\end{array}$ & $\begin{array}{l}0.281 * * * \\
(0.070)\end{array}$ \\
\hline Age & $\begin{array}{l}-0.011 \\
(0.008)\end{array}$ & $\begin{array}{c}-0.042 * * * \\
(0.012)\end{array}$ & $\begin{array}{c}0.000 \\
(0.008)\end{array}$ & $\begin{array}{c}-0.037 * * * \\
(0.010)\end{array}$ \\
\hline $\mathrm{Age}^{2}$ & $\begin{array}{c}0.000 \\
(0.000)\end{array}$ & $\begin{array}{c}0.000 * * * \\
(0.000)\end{array}$ & $\begin{array}{c}0.000 \\
(0.000)\end{array}$ & $\begin{array}{c}0.000 * * * \\
(0.000)\end{array}$ \\
\hline Have Children & $\begin{array}{c}0.010 \\
(0.055)\end{array}$ & $\begin{array}{c}0.094 \\
(0.073)\end{array}$ & $\begin{array}{c}0.007 \\
(0.051)\end{array}$ & $\begin{array}{c}0.060 \\
(0.069)\end{array}$ \\
\hline Some College or More & $\begin{array}{l}-0.022 \\
(0.050)\end{array}$ & $\begin{array}{l}-0.039 \\
(0.070)\end{array}$ & $\begin{array}{c}-0.109 * * \\
(0.044)\end{array}$ & $\begin{array}{l}-0.024 \\
(0.065)\end{array}$ \\
\hline 2nd Income Quartile & $\begin{array}{l}-0.003 \\
(0.076)\end{array}$ & $\begin{array}{c}0.243 * * \\
(0.101)\end{array}$ & $\begin{array}{c}0.002 \\
(0.063)\end{array}$ & $\begin{array}{c}0.058 \\
(0.100)\end{array}$ \\
\hline 3rd Income Quartile & $\begin{array}{l}-0.143 * \\
(0.076)\end{array}$ & $\begin{array}{c}0.281 * * \\
(0.114)\end{array}$ & $\begin{array}{c}-0.142 * * \\
(0.072)\end{array}$ & $\begin{array}{c}0.108 \\
(0.103)\end{array}$ \\
\hline 4th Income Quartile & $\begin{array}{c}-0.202 * * * \\
(0.069)\end{array}$ & $\begin{array}{c}0.317 * * * \\
(0.101)\end{array}$ & $\begin{array}{c}-0.134 * * \\
(0.063)\end{array}$ & $\begin{array}{l}0.260 * * * \\
(0.087)\end{array}$ \\
\hline Employed & $\begin{array}{c}0.032 \\
(0.106)\end{array}$ & $\begin{array}{c}0.325 * * \\
(0.131)\end{array}$ & $\begin{array}{l}-0.006 \\
(0.062)\end{array}$ & $\begin{array}{l}0.383 * * * \\
(0.102)\end{array}$ \\
\hline Unemployed & $\begin{array}{c}0.224 \\
(0.153)\end{array}$ & $\begin{array}{c}0.030 \\
(0.213)\end{array}$ & $\begin{array}{l}-0.059 \\
(0.146)\end{array}$ & $\begin{array}{c}0.099 \\
(0.220)\end{array}$ \\
\hline Retired & $\begin{array}{c}0.327 * * * \\
(0.126)\end{array}$ & $\begin{array}{c}0.629 * * * \\
(0.191)\end{array}$ & $\begin{array}{c}0.093 \\
(0.090)\end{array}$ & $\begin{array}{l}0.575 * * * \\
(0.157)\end{array}$ \\
\hline Interview times & Yes & Yes & Yes & Yes \\
\hline R-squared & 0.066 & 0.126 & 0.044 & 0.078 \\
\hline Number of Observations & 3,930 & 2,028 & 4,583 & 2,524 \\
\hline
\end{tabular}

Note: This table replicates Table 2 using the UK time-use surveys in 2014-15. 


\section{Appendix D. Additional Figures}

Appendix Figure 1. Distribution of happiness scores in 1985 and 2013.
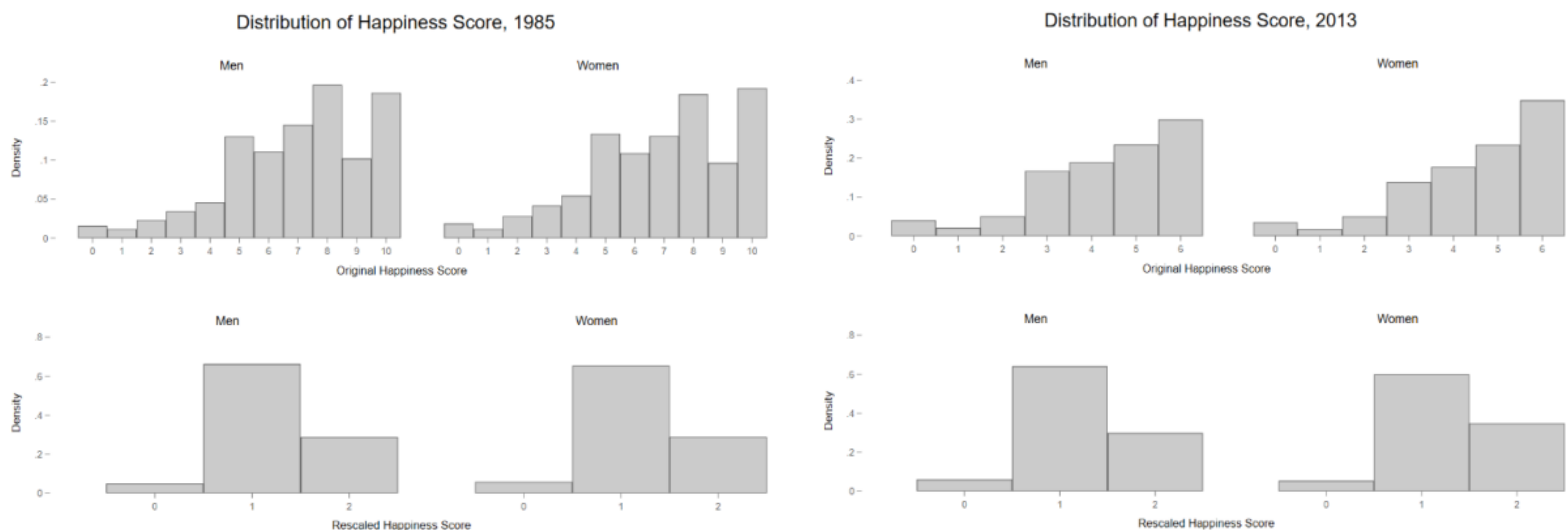

Note: This figure plots the distributions of happiness scores before and after rescaling for men and women in 1985 and 2013 . The rescaled happiness (bottom) measure is on a 3-point scale ranging from 0 to 2 . In particular, scores 0 to 2 from the 11 -point 1985 survey are converted to a 0 , scores of 3-8 are converted to a 1 , and scores 9-10 are converted to a 2 . In 2013, the original scores of $0-1$ are converted to a 0 , while the original scores of $2-5$ and 6 are converted to 2 and 3 , respectively. 
Appendix Figure 2. Unadjusted and FE-adjusted happiness by activity, 1985 and 2013
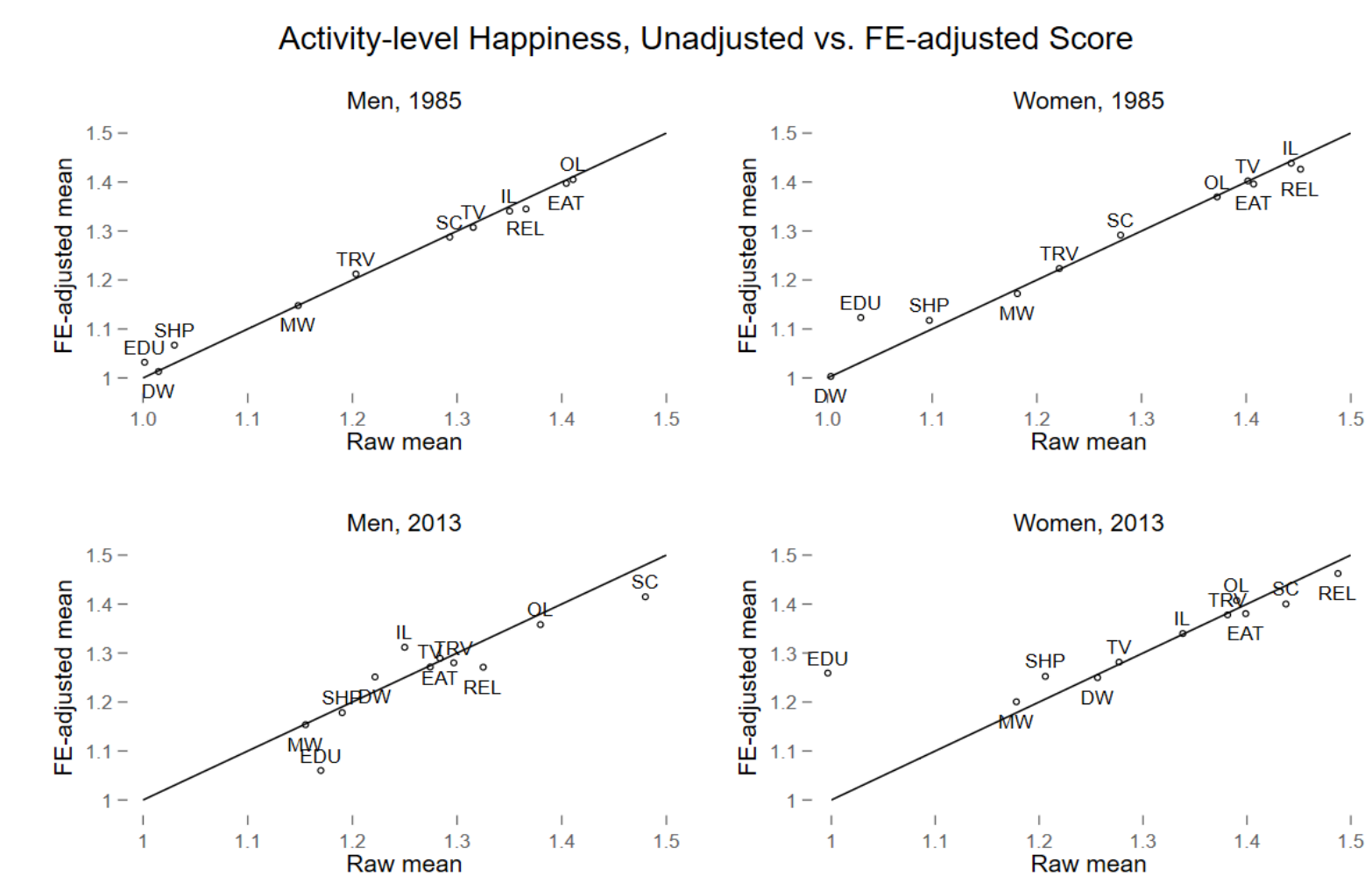

Note: This figure compares the FE-adjusted average happiness (y-axis) against the unadjusted average happiness by activity (xaxis) for men and women in 1985 and 2013. The fixed effect adjusted happiness is estimated from regressing the harmonized 3point scale happiness measure on activity indicators and individual fixed effects. MW: market work, DM: domestic work, SHP: shopping, TRV: travel excluding work related travel, EAT: eating, OL: out of home leisure, TV: watching TV, IL: in home leisure excluding watching TV, SC: social care, EDU: education, REL: civic/religious activities. 
Appendix Figure 3. Activity-level happiness and time allocation by gender using 46 activity categories
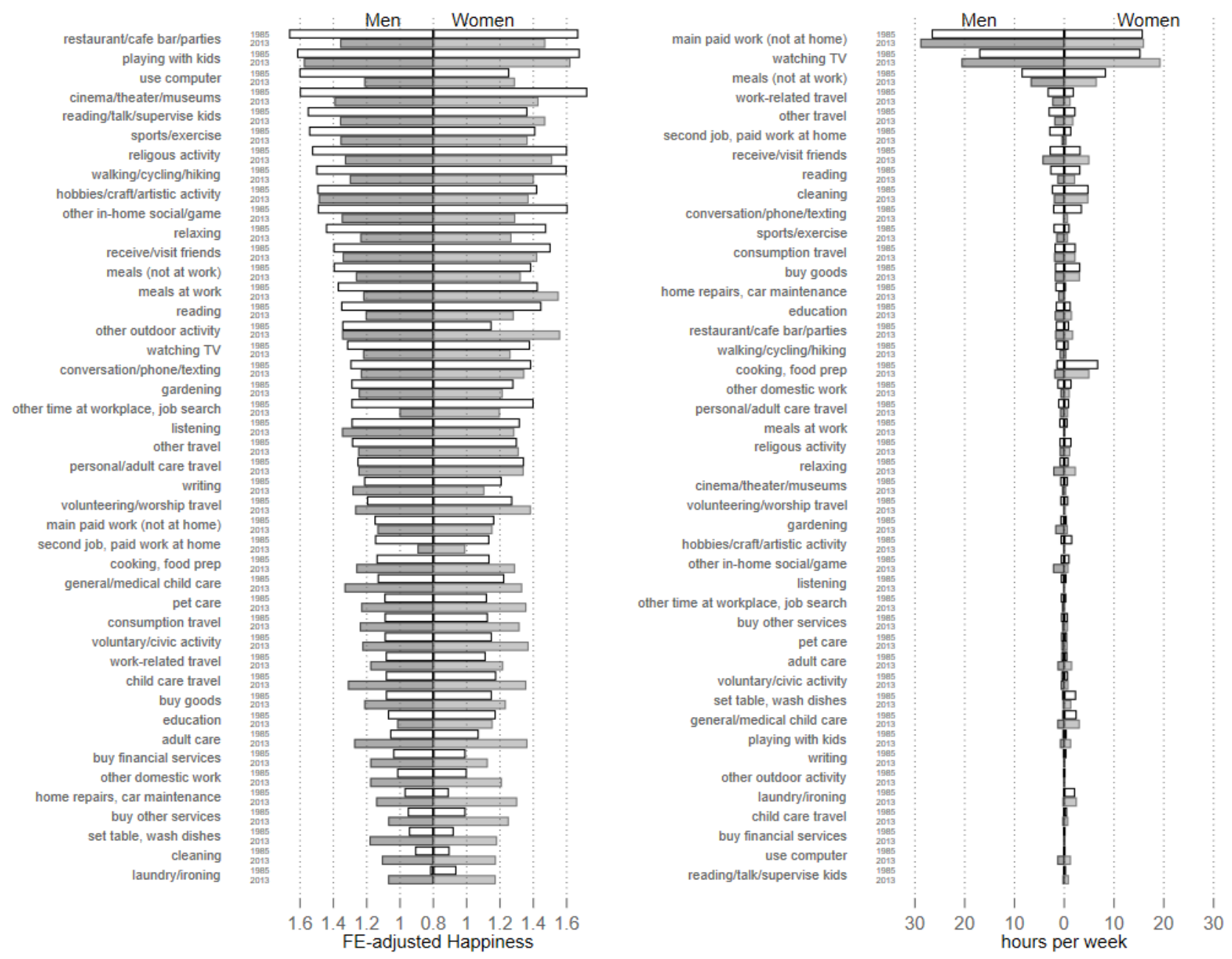

Note: This figure replicates Figure 1 using 46 activity categories. 
Appendix Figure 4. Relationship between Activity-level Happiness and Duration of Activity using 46 Activity Categories
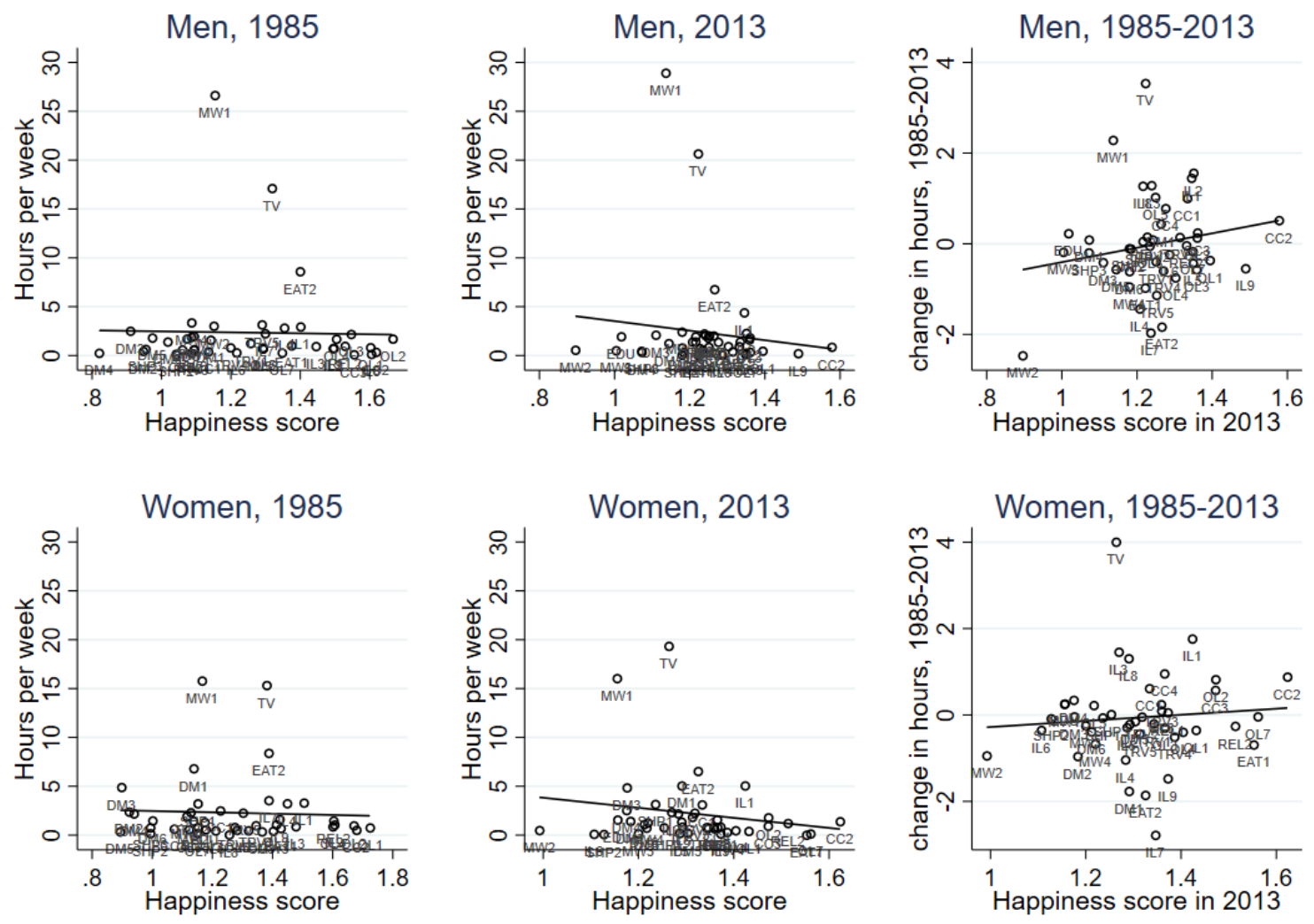

Note: This figure replicates Figure 2 using the 46 activity categories. 
Appendix Figure 5. Polynomial regression of time-use on reported happiness

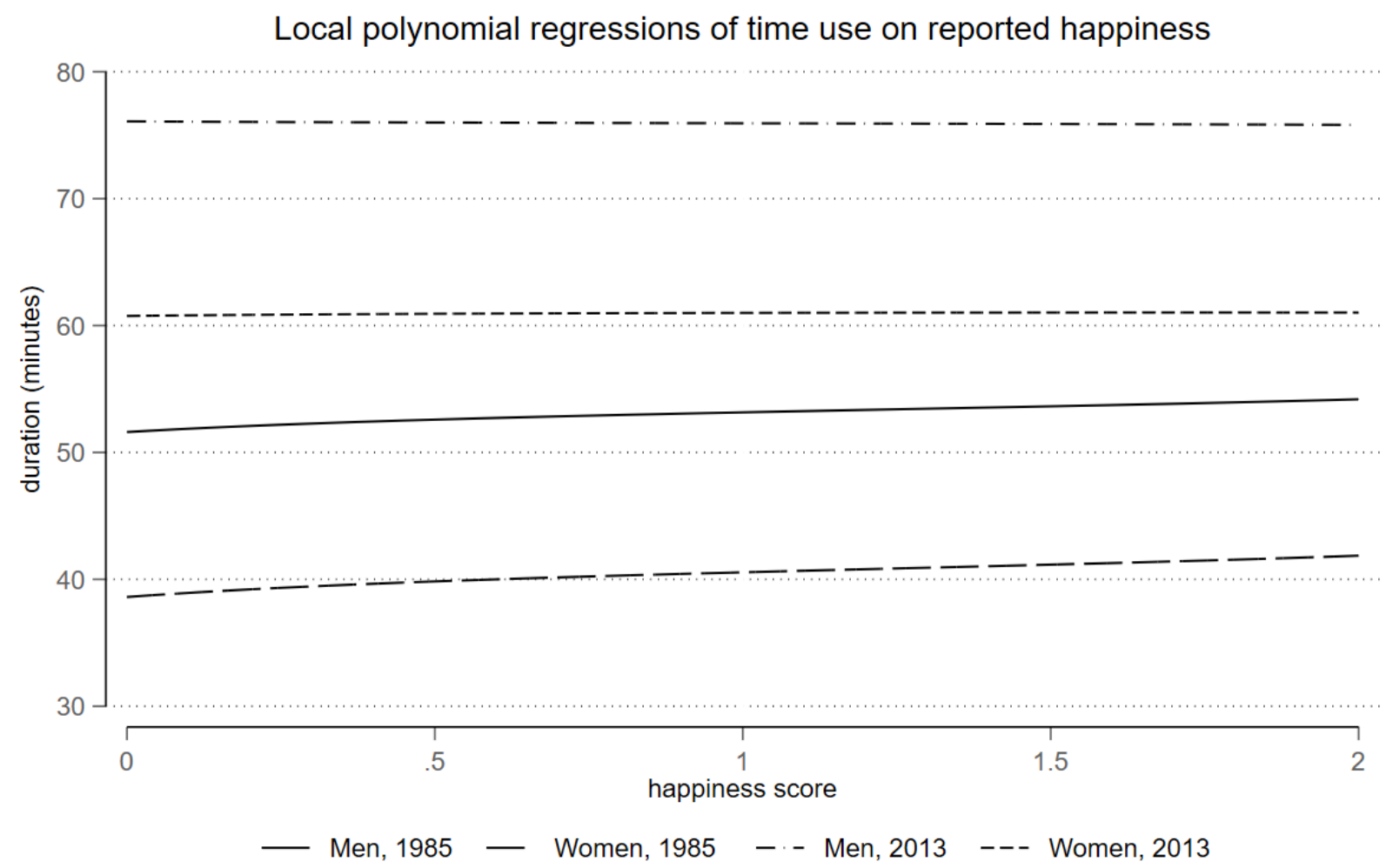

Note: This figure shows the results of local polynomial regressions of minutes spent on individual activities on reported happiness score. Regressions are run separately for 1985 and 2013 data, and across genders. For a given happiness score, men always spent more time than women on an individual activity. For a given happiness score, both genders spent more time on the same activity in 2013 than in 1985. However, as shown by the horizontal regression lines, the length of time spent on individual activities and reported happiness score are unrelated within each year-gender combination. 
Appendix Figure 6. Time-weighted Happiness by Gender using 46 Activity Categories

\section{Time-weighted happiness, 1985-2019}

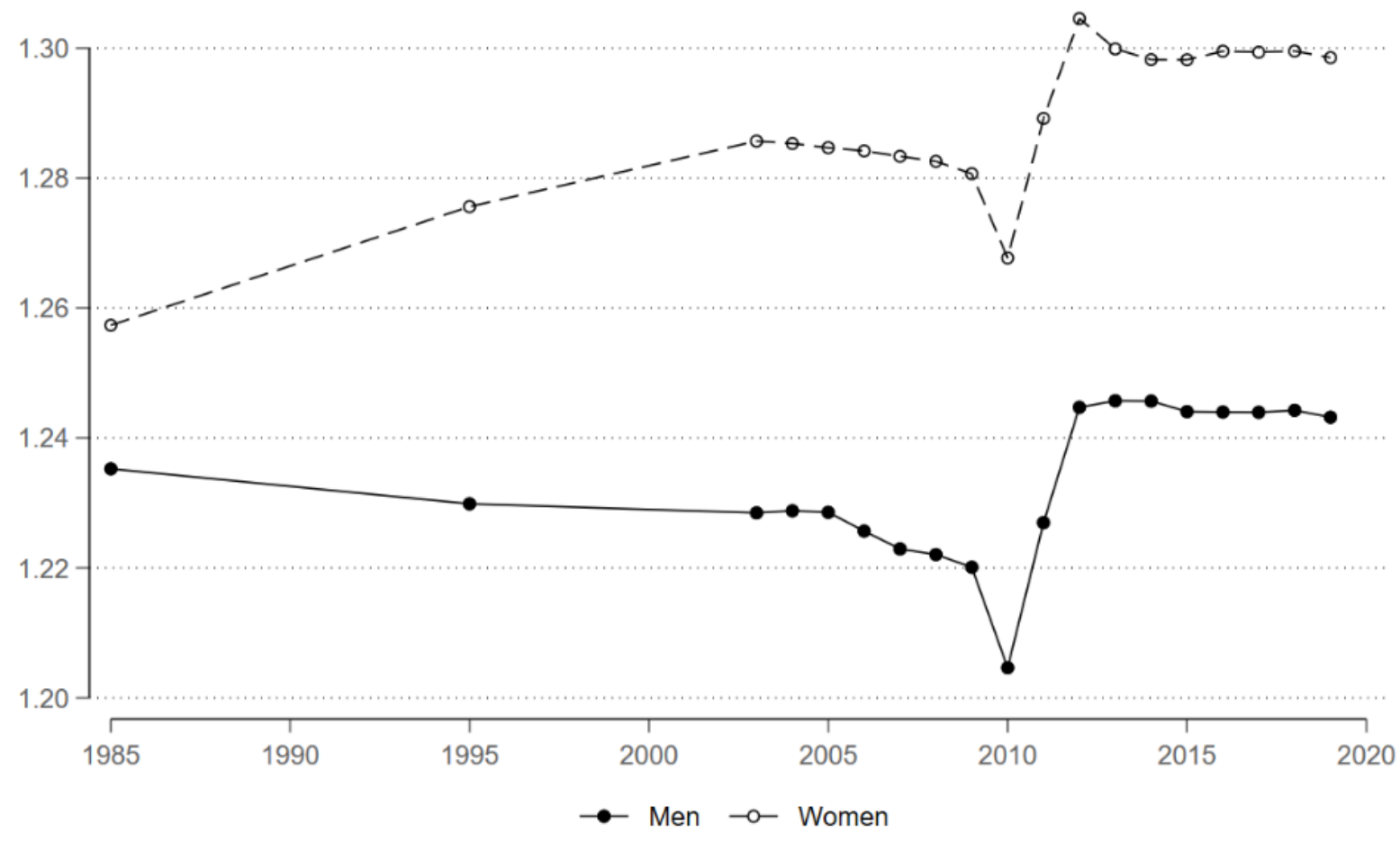

Note: This figure replicates Figure 3 using the 46 activity categories. Estimates are weighted using fixed demographic weights. 
Appendix Figure 7. Decomposition of Time-weighted Happiness, 1985 and 2019

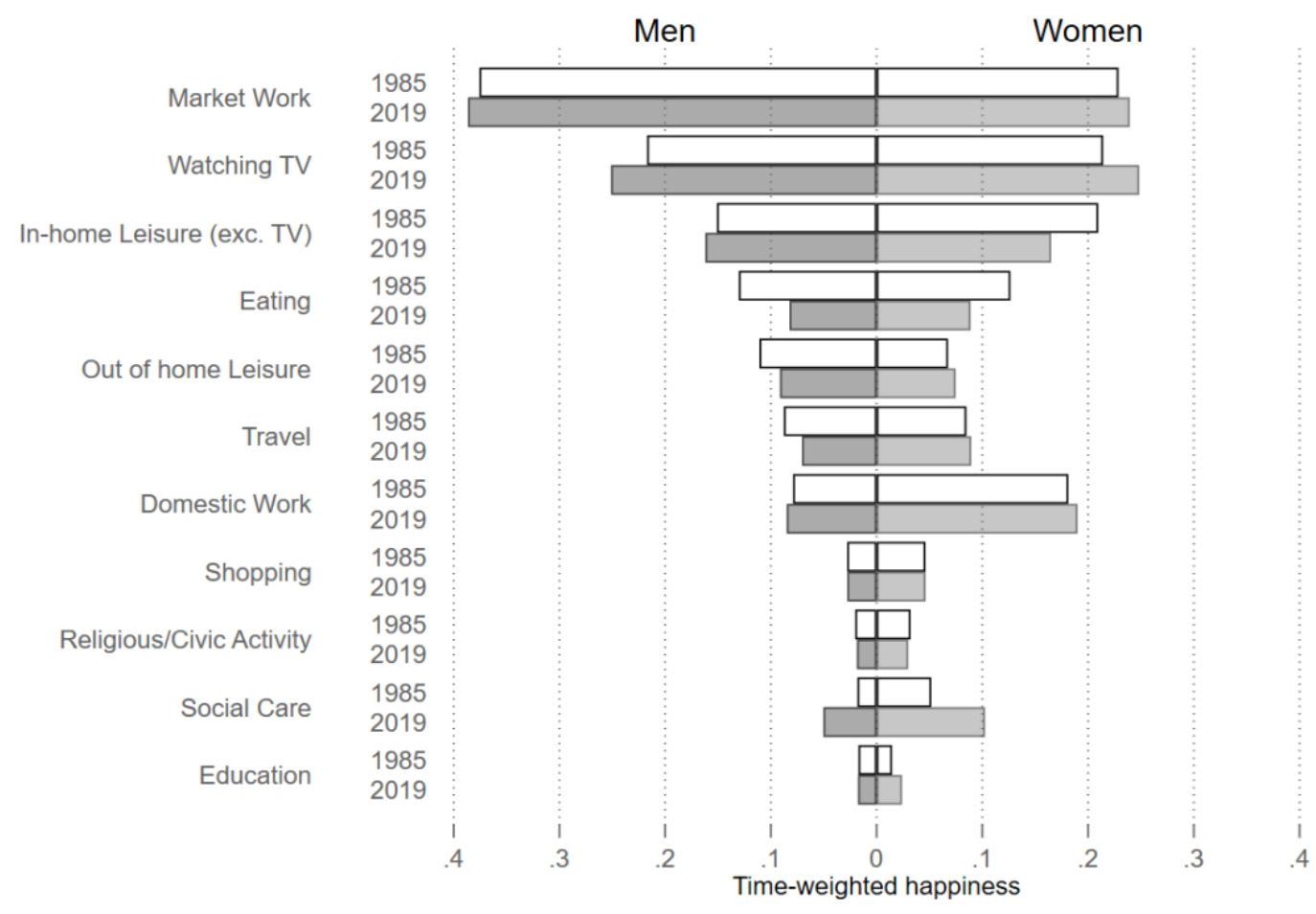

Note: This figure reports components of the aggregate happiness for men and women in 1985 and 2019, with each component representing each activity's contribution to the aggregate happiness. Each component is calculated as the fixed effect adjusted happiness for a given activity weighted by the average amount of time spent on the activity. 
Appendix Figure 8a Activity-level Happiness by subgroup, 1985 and 2013
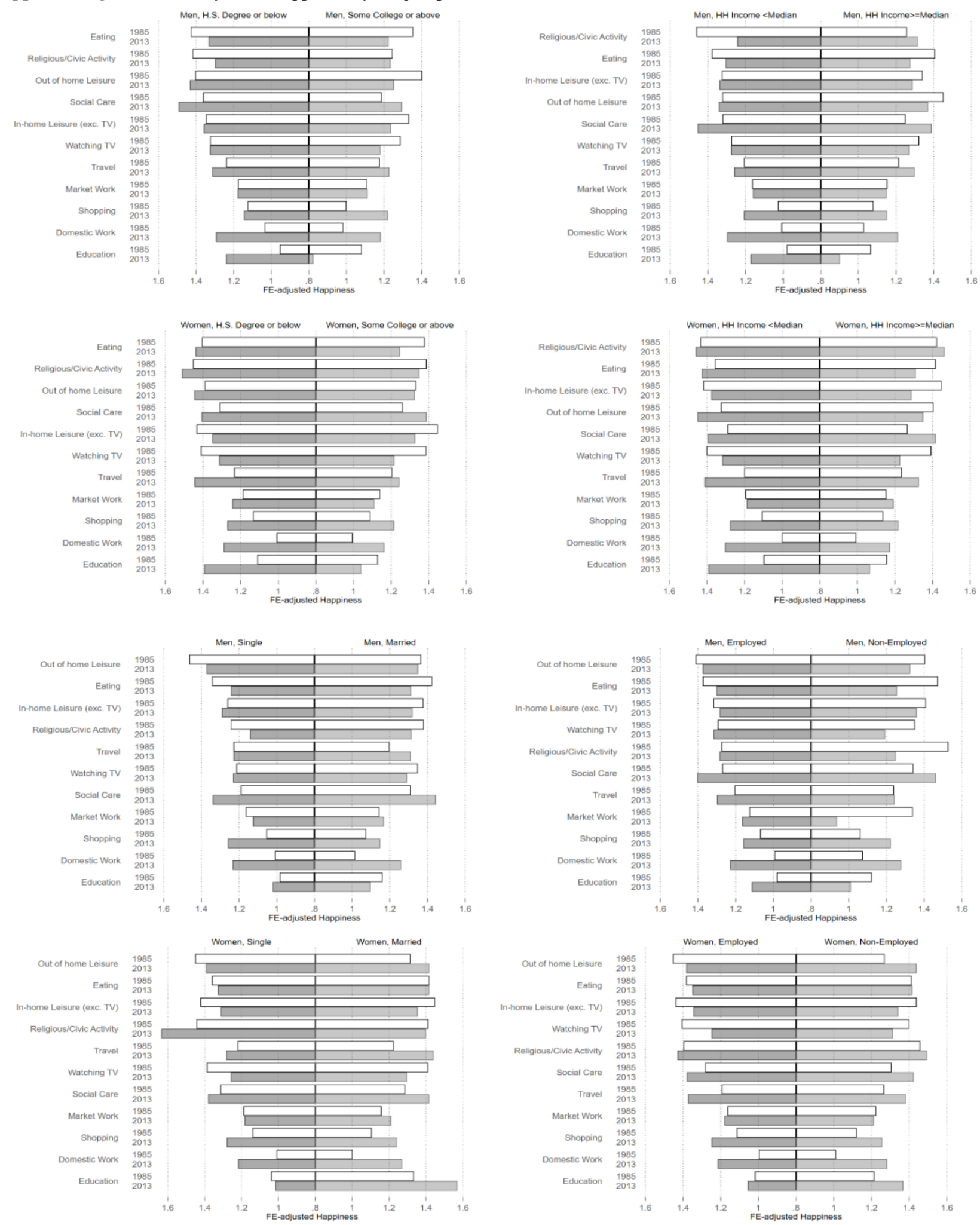

Note: This figure reports mean FE-adjusted levels of happiness across activities by gender and education (top-left), income (topright), marital status (bottom-left), and employment status (bottom-right). 
Appendix Figure 8b Time allocation by subgroup, 1985 and 2013
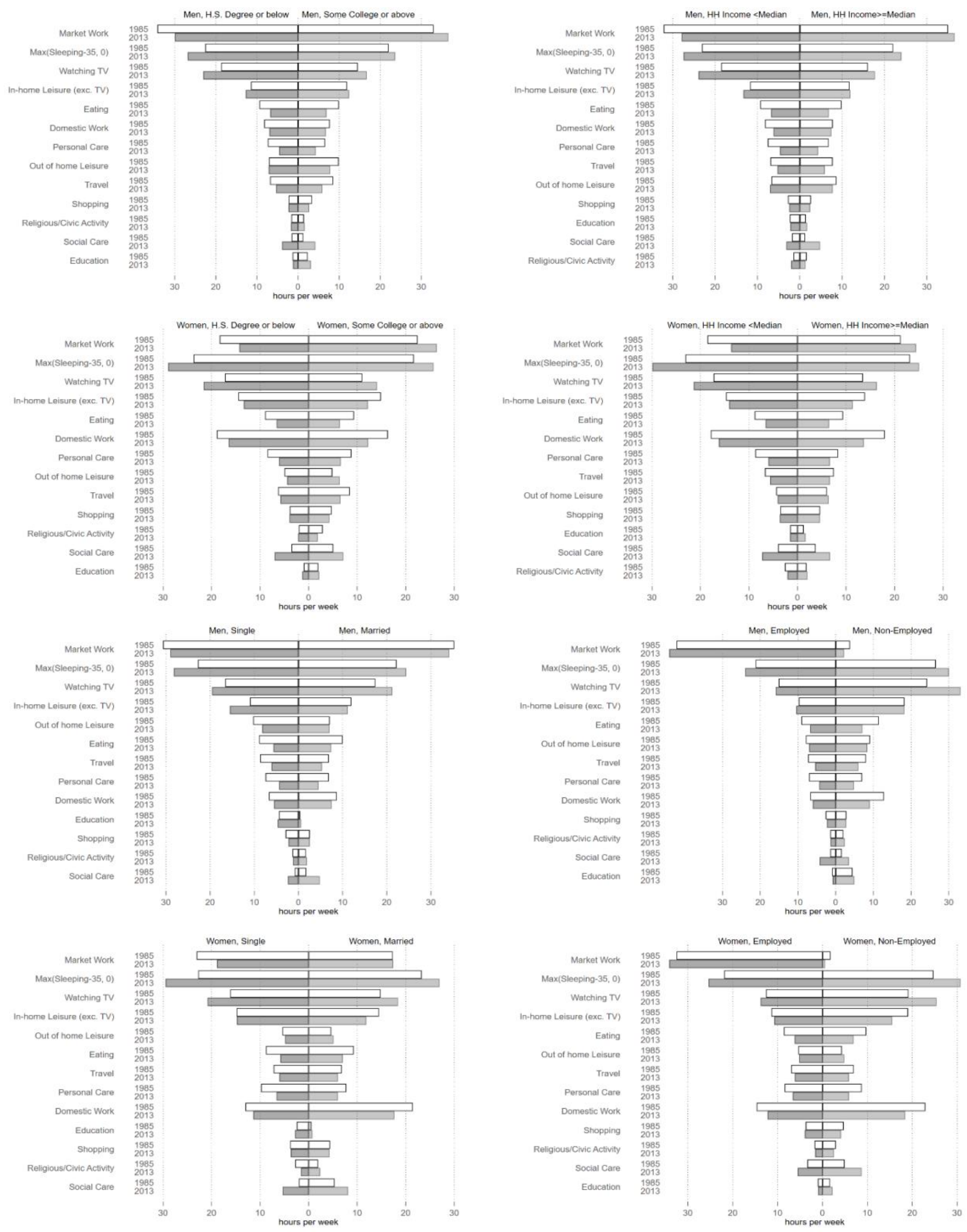

Note: This figure reports average weekly time-use across activities by gender and education (top-left), income (top-right), marital status (bottom-left), and employment status (bottom-right). 
Appendix Figure 9a. Time-weighted happiness constraining activity-level happiness to be equal across sub-groups
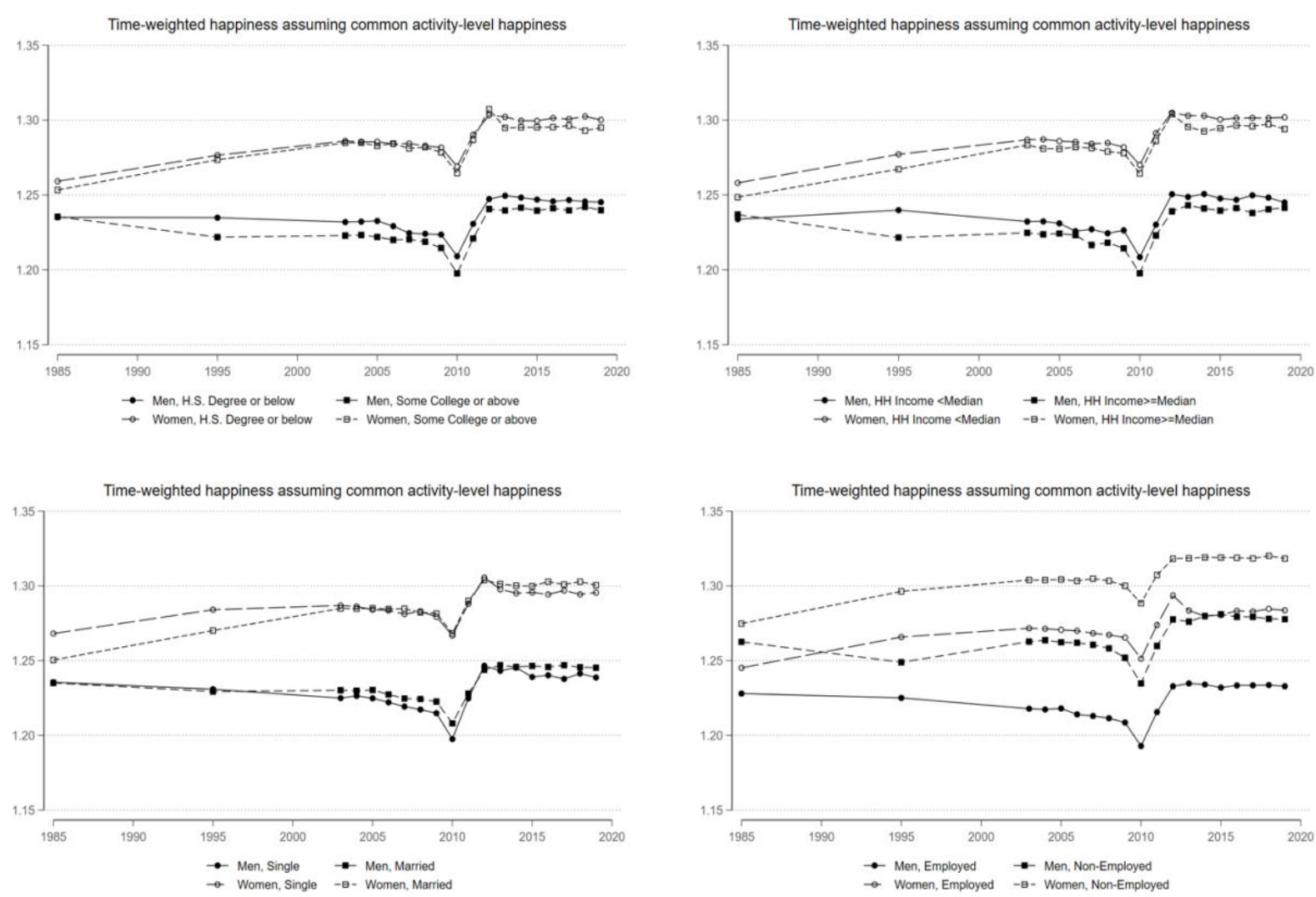

Note: This figure plots changes in the aggregate happiness by gender and education (top-left), income (top-right), marital status (bottom-left), and employment status (bottom-right) when constraining activity-level happiness to be equal across sub-groups. Estimates are weighted using fixed demographic weights. 


\section{TIME USE AND HAPPINESS: EVIDENCE ACROSS THREE DECADES}

Appendix Figure 9b. Time-weighted happiness constraining time allocation to be equal across sub-groups
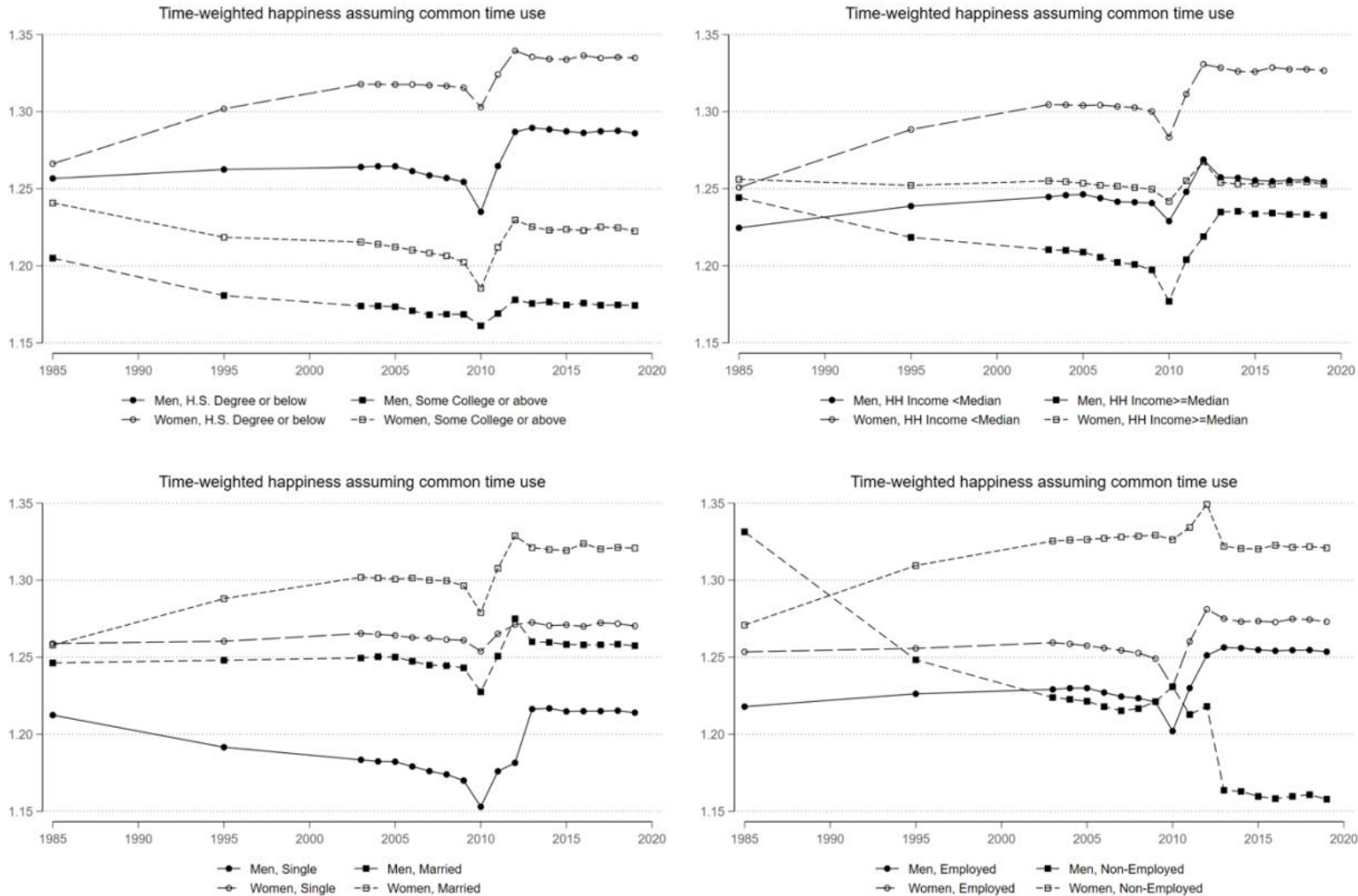

Note: This figure plots changes in the aggregate happiness by gender and education (top-left), income (top-right), marital status (bottom-left), and employment status (bottom-right) when constraining time allocation to be equal across sub-groups. Estimates are weighted using fixed demographic weights. 
Appendix Figure 10 Activity-level happiness by gender using ordered probit, 1985 and 2013

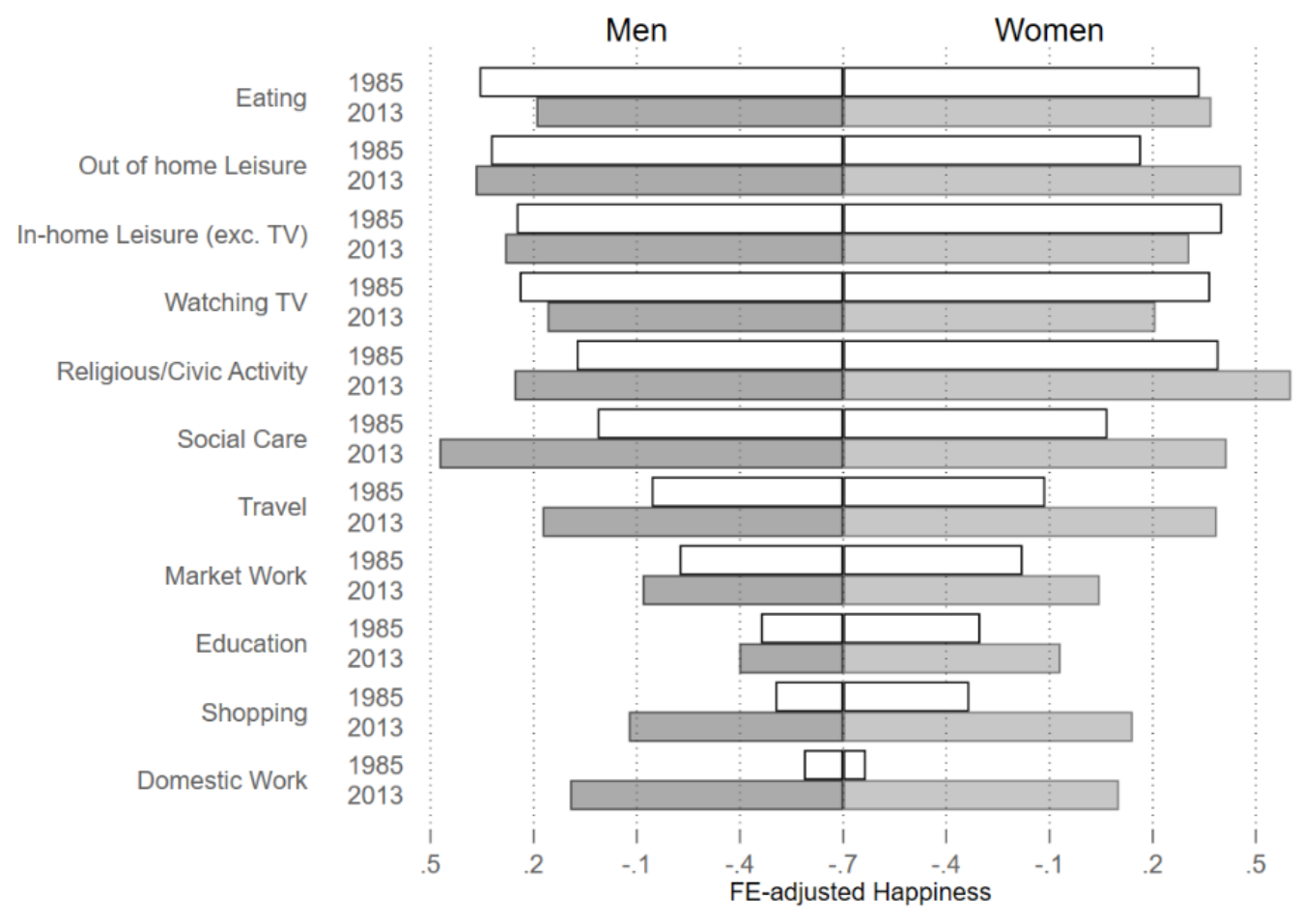

Note: This figure reports mean FE-adjusted levels of happiness across activities for men and women where FE-adjusted happiness is estimated via ordered probit regressions. 
Appendix Figure 11. Time-weighted happiness using binary happiness measures

(A) Not happy: 0-1 (1985) and 0 (2010-13)

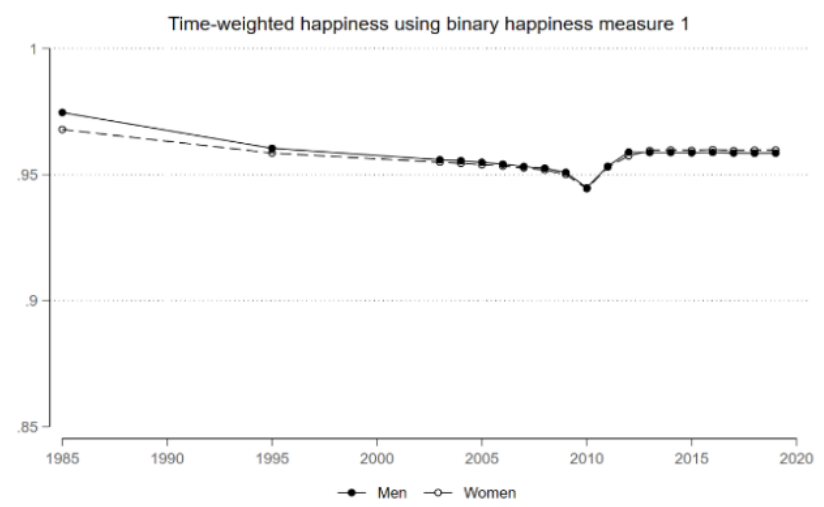

(C) Not happy: 0-3 (1985) and 0-2 (2010-13)

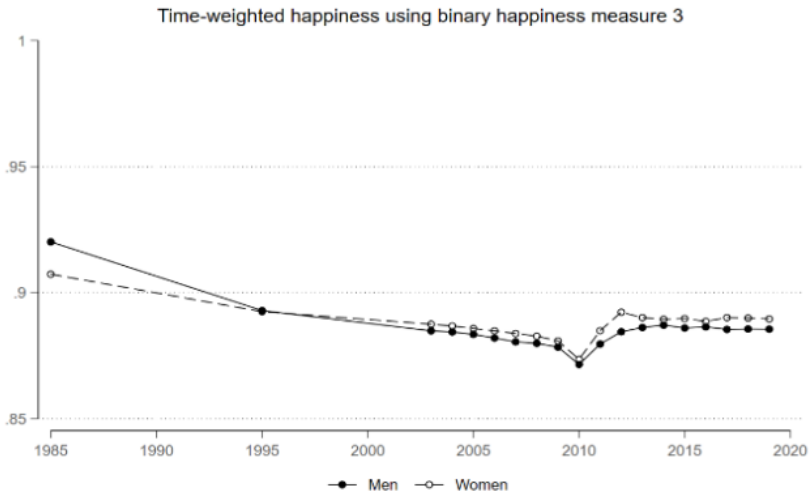

(E) Not happy: 0-6 (1985) and 0-4 (2010-13)

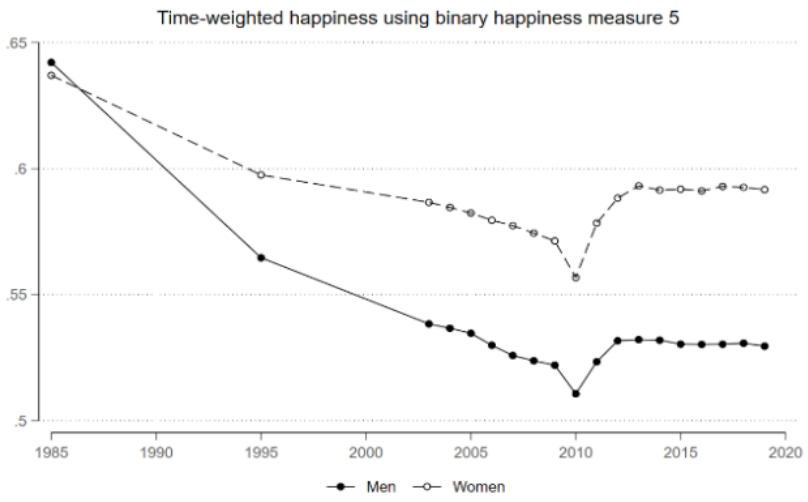

(B) Not happy: 0-2 (1985) and 0-1 (2010-13)

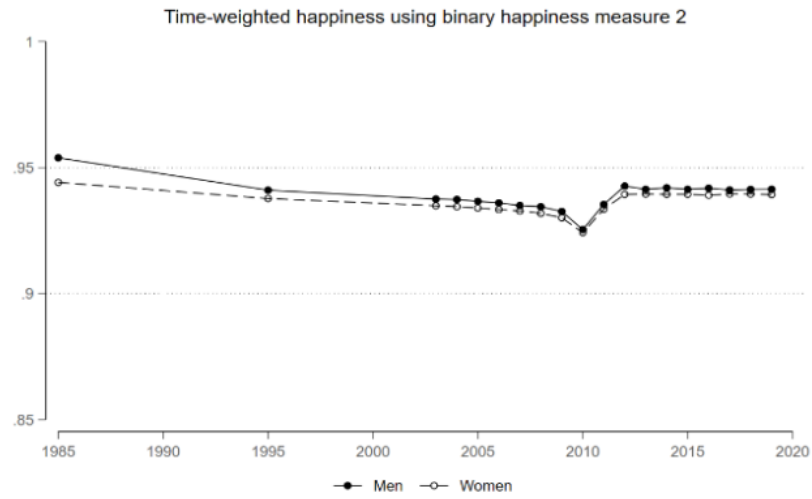

(D) Not happy: 0-5 (1985) and 0-3 (2010-13)

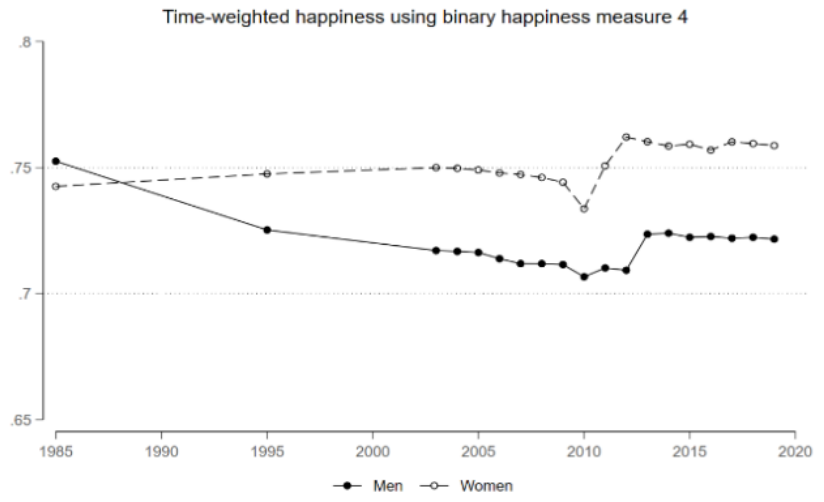

(F) Not happy: 0-8 (1985) and 0-5 (2010-13)

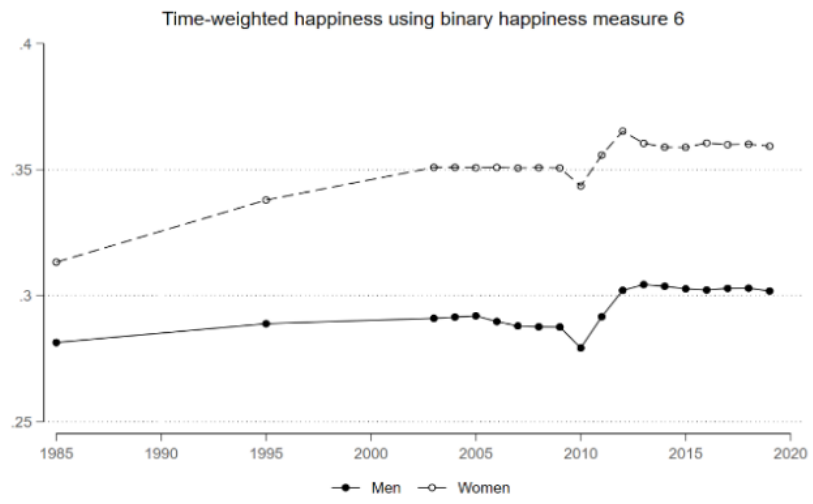

Note: This figure replicates Figure 3 using six binary happiness measures. Estimates are weighted using fixed demographic weights. 


\section{TIME USE AND HAPPINESS: EVIDENCE ACROSS THREE DECADES}

Appendix Figure 12. Activity-level happiness and time-allocation by Gender, UKTUS 1986 and 2014-15
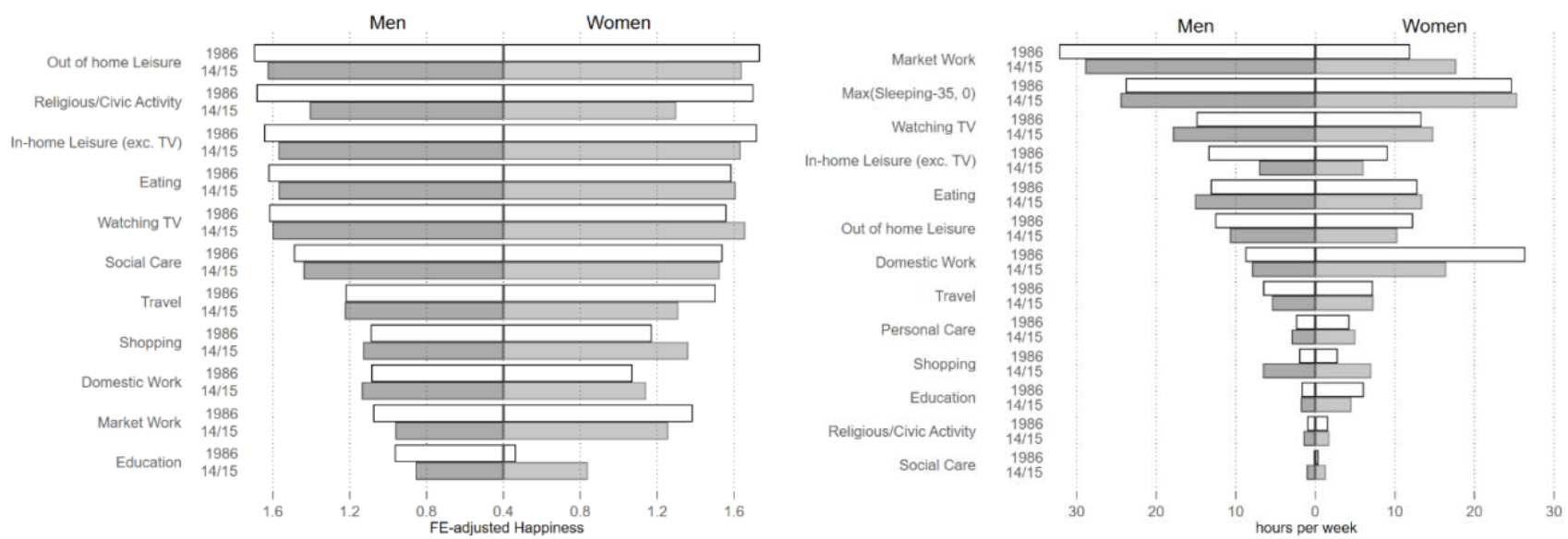

Note: This figure replicates Figure 1 using the UK time-use surveys in 1986 and 2014-15. The sample month is restricted to June and July only. 
Appendix Figure 13. Relationship between Activity-level Happiness and Duration of Activity, UKTUS 1986 and 2014-15
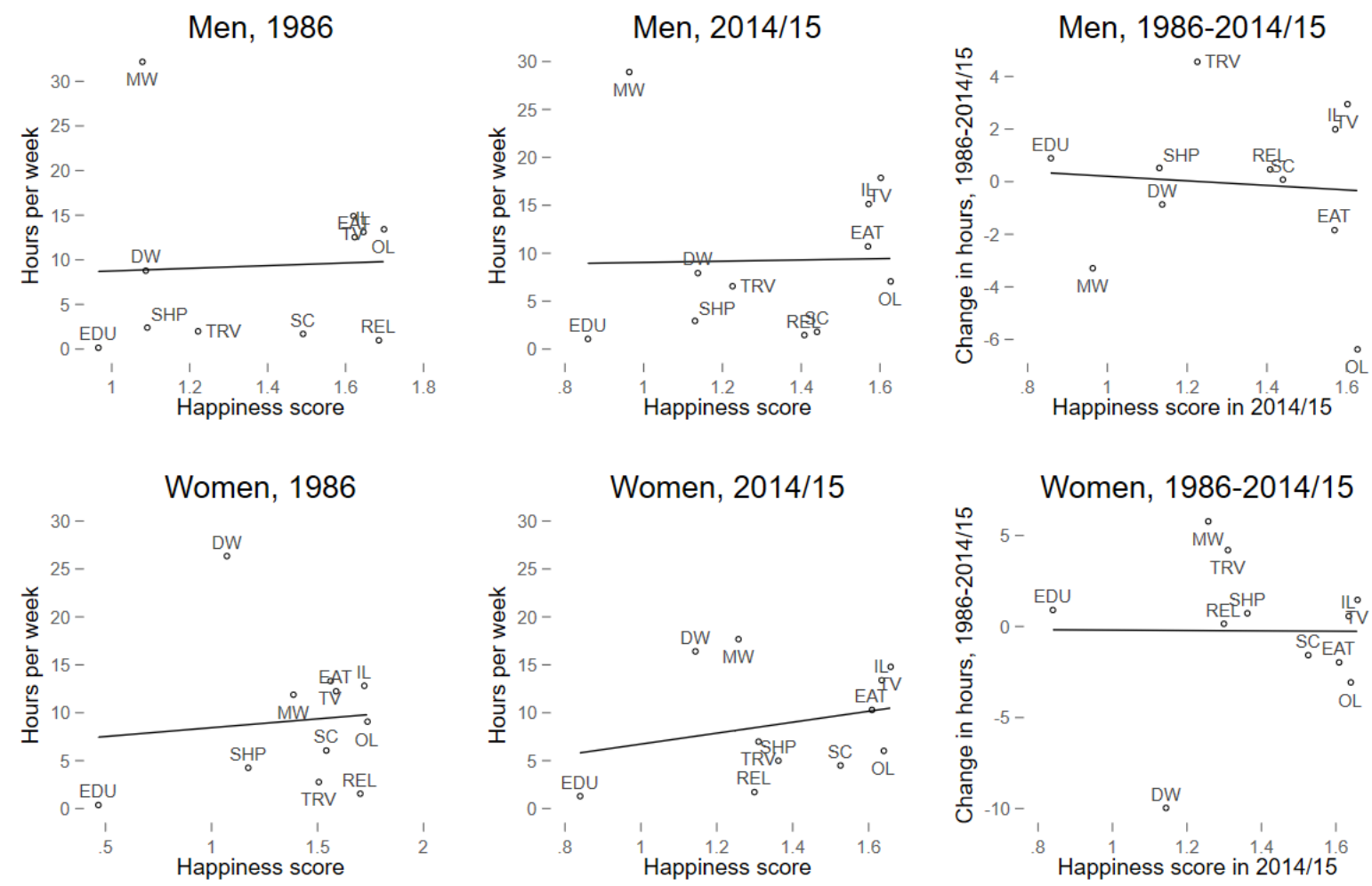

Note: This figure replicates Figure 2 using the UK time-use surveys in 1986 and 2014-15. The sample month is restricted to June and July because the 1986 data is collected in June and July only. Estimates are weighted using fixed demographic weights. MW: market work, DM: domestic work, SHP: shopping, TRV: travel excluding work related travel, EAT: eating, OL: out of home leisure, TV: watching TV, IL: in home leisure excluding watching TV, SC: social care, EDU: education, REL: civic/religious activities. 
Appendix Figure 14. Time-weighted Happiness by Gender, UKTUS 1986-2015

Time-weighted happiness, UKTUS 1986-2014/15

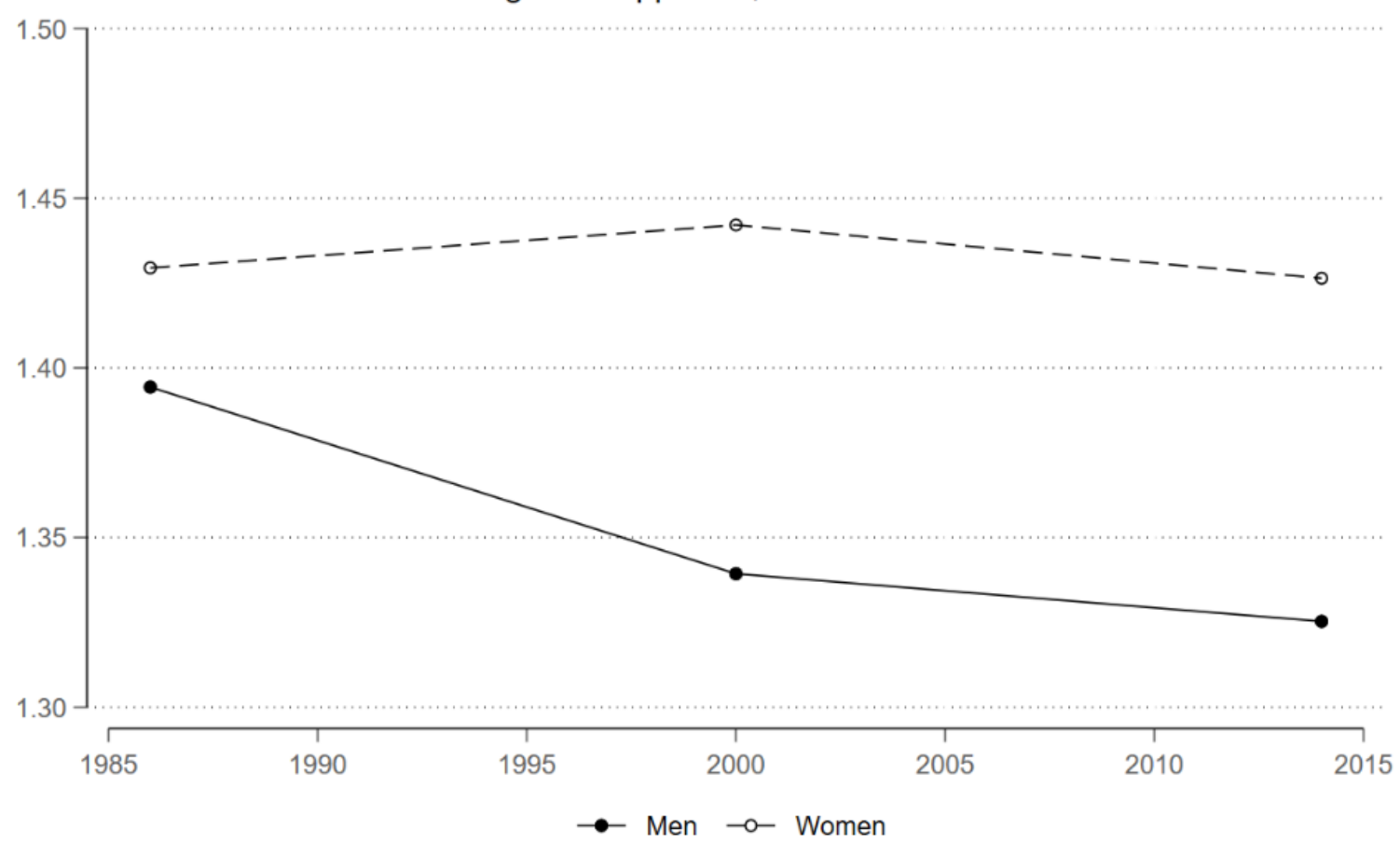

Note: This figure replicates Figure 3 using the UK time-use surveys in 1986, 2000-01, and 2014-15. The sample month is restricted to June and July only. Estimates are weighted using fixed demographic weights. 
Appendix Figure 15. Time-weighted Happiness by Gender, 4-point Common Scale

Time-weighted happiness, 1985-2019

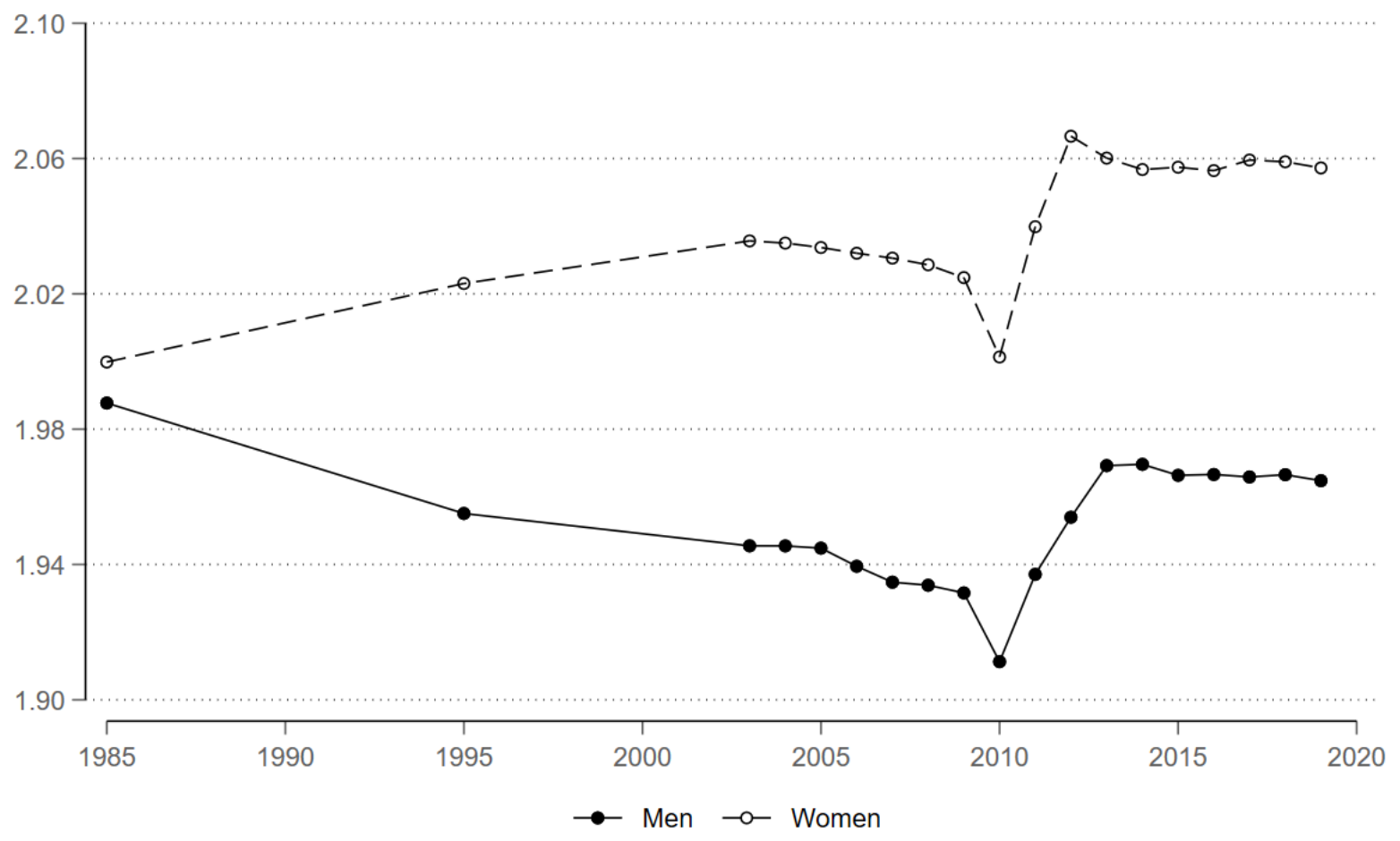

Note: This figure replicates Figure 3 using the 4-point common scale, instead of the 3-point common scale. In the 1985 data, scores 0-2 are converted to a 0 , scores 3-5 are converted to a 1, scores 6-8 are converted to a 2, and scores of 9-10 are converted to a 3. For the 2010-2013 data, the scores 0-1 are converted to a 0, scores 2-3 are converted to a 1, scores 4-5 are converted to a 2, and scores of 6 are converted to a 3. Estimates are weighted using fixed demographic weights. 
Appendix Figure 16. Time-weighted Happiness by Gender, Survey Weights

Time-weighted happiness, 1985-2019

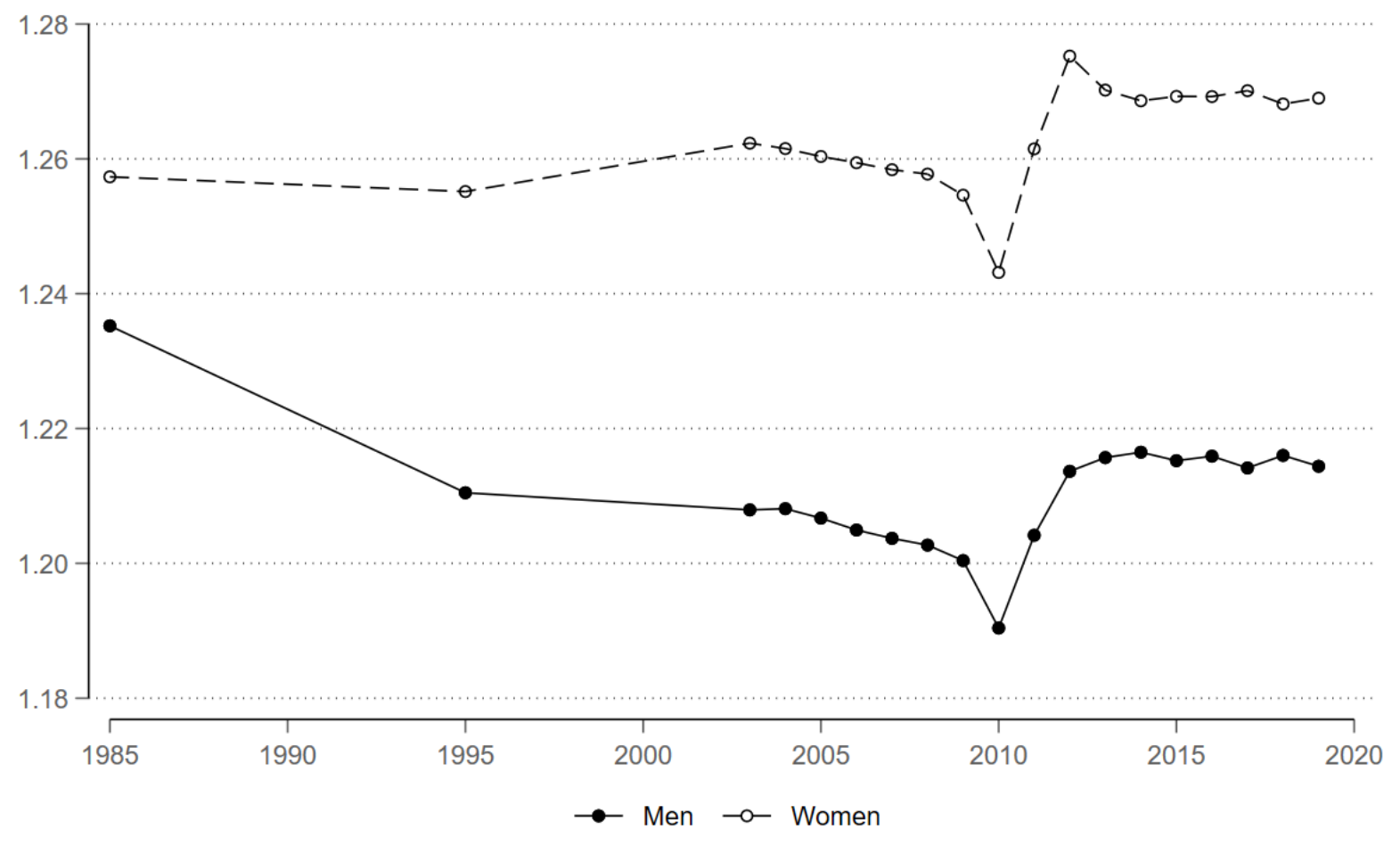

Note: This figure replicates Figure 3 using survey weights, instead of fixed demographic weights. 
Appendix Figure 17. Association of income with life satisfaction and time-weighted happiness, ATUS 2012-2013

\section{Average time-weighted happiness and life satisfaction at each observed income level (2012-2013)}
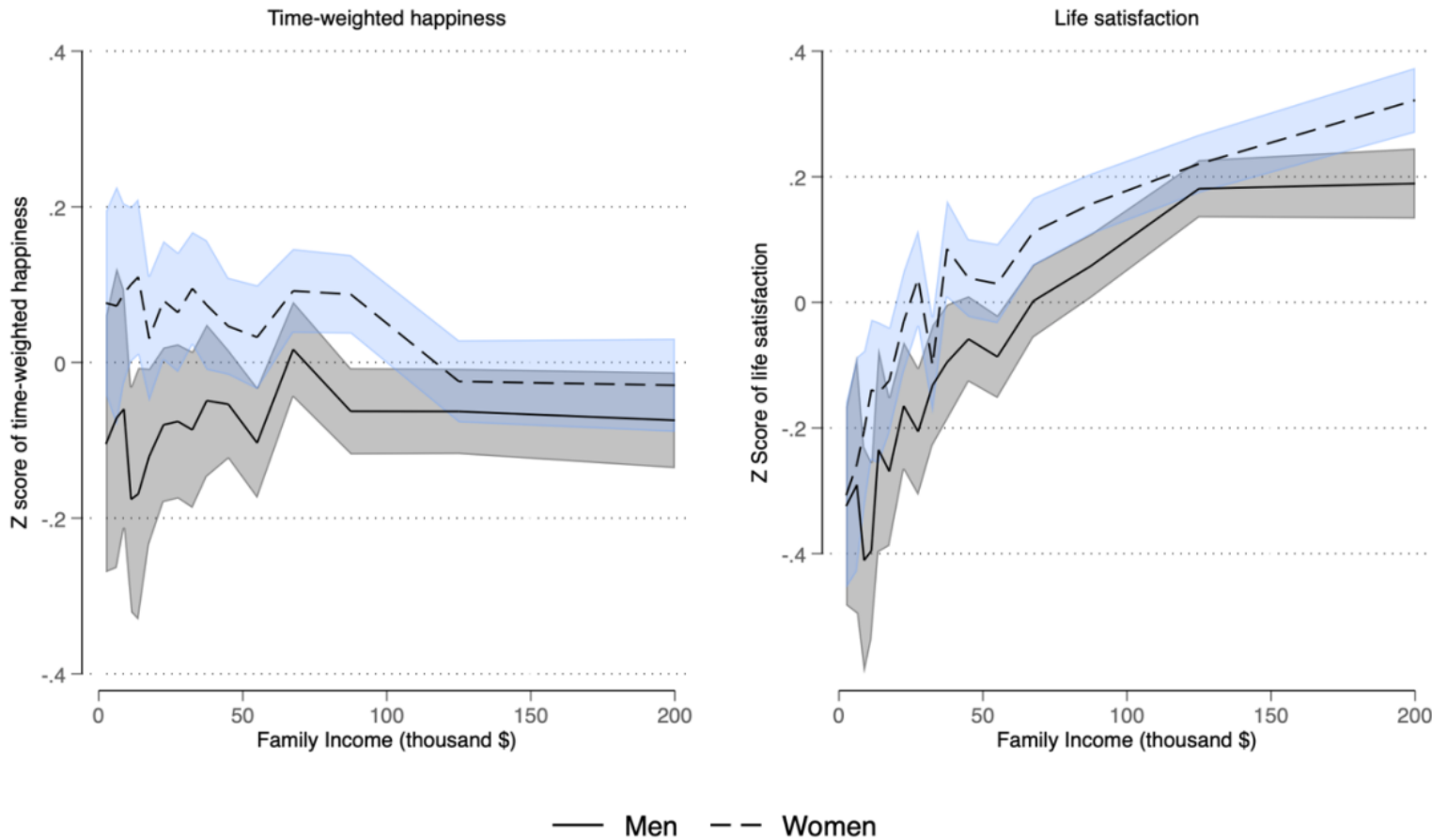

Note: Shaded regions are 95\% confidence intervals. Estimates are weighted using fixed demographic weights. 